\title{
EL RECETARIO IMPAGADO DE UN RECTOR DE LA UNIVERSIDAD DE VALLADOLID EN EL SIGLO XVI*
}

\author{
A PAD OF UNPAID PRESCRIPTIONS OF A CHANCELLOR OF THE \\ UNIVERSITY OF VALLADOLID IN THE SIXTEENTH CENTURY
}

\author{
Mauricio Herrero Jiménez \\ LUIS TAMAYO LOMAS \\ Universidad de Valladolid \\ herrero@fyl.uva.es \\ luistalo@hotmail.com
}

RESUMEN: El trabajo que presentamos tiene como objeto fundamental la edición y estudio de las recetas halladas en un pleito litigado en el tribunal de la Chancillería de Valladolid, al que llegaron porque Félix de Manzanedo, rector de la Universidad y Oidor del citado tribunal, no se las pagó al boticario Francisco de Madrid ni a su viuda, María de Ayala, que es quien reclama la deuda y demandó al catedrático. A través del análisis de las recetas se pueden conocer los nombres de dos de los médicos más importantes de Valladolid en el siglo XVI, Juan de Peñaranda y Pedro Enríquez, así como el conocimiento que tienen, tanto ellos como el boticario que las expende, de las sustancias medicinales y el modo en que se preparan y combinan en los años medios del siglo.

PALABRAS CLAVE: Farmacia, medicina, recetas, Valladolid, universidad.

ABSTRACT: The present paper aims to offer an edition and study of some prescriptions included in a sixteenth-century lawsuit litigated in the Real Chancilleria of Valladolid. María of Ayala, the widow of the apothecary Francisco of Madrid, sued Félix Manzanedo, chancellor of the University of Valladolid and magistrate in the aforesaid court, because he had failed to pay his long-standing debt to the apothecary, and she substantiated her claim with the prescriptions his deceased husband kept. By studying these prescriptions it becomes possible to ascertain the names of two of Valladolid's most prestigious doctors in the mid-sixteenth century: Juan of Peñaranda and Pedro Enríquez. They give us also an insight into the knowledge that both the doctors and the apothecary had of the active ingredient of

\footnotetext{
* Queremos agradecer al personal del Archivo de la Real Chancillería de Valladolid las facilidades que nos ha dado (y da siempre) para trabajar en el centro y, en este caso, además,por la restauración y exposición de las recetas que nos ha permitido la realización de este trabajo.
} 
medications and into their ability to prepare and combine those ingredients in their efforts to create effective treatments.

KEYWORDS: Pharmacy, medicine, prescriptions, Valladolid, university.

\section{INTRODUCCIÓN}

Se lamenta desconcertado el hábil Tristán en El perro del hortelano, cuando su señor, Teodoro, rompe al entregárselo el billete amoroso de Marcela: Basta; que sois los amantes / boticarios del amor; / que, como ellos las recetas, / vais ensartando papeles ${ }^{1}$.

Y en una sarta de recetas (que no son de amor) está el origen de este trabajo, en el que nos proponemos estudiar todo lo concerniente a las cédulas impagadas, al recetario enhebrado en la segunda mitad del siglo XVI en un cordel de cuero que María de Ayala, viuda del boticario Francisco de Madrid, presentó en el tribunal de la Real Chancillería de Valladolid.

Las boticas y boticarios de la villa primero y ciudad después del Pisuerga no son desconocidos, han sido objeto de estudio en diferentes trabajos. Muchos de los cuales tienen como punto de partida los inventarios de boticas y, en menor medida, las visitas hechas a las especierías ${ }^{2}$. La información que estas fuentes proporcionan es de un valor extraordinario. Los protocolos notariales y los procesos sustanciados en los tribunales de justicia, en los que se encuentran inventarios y visitas, se han convertido en un notorio recurso de información. De la información que contienen, claro está, las fuentes documentales.

En un documento de archivo se encuentra el recetario, las recetas no pagadas que María de Ayala pretendía cobrar. La fortuna ha querido ponernos en la mano esos apuntes, de los que se sirvieron los médicos para ordenar al boticario Francisco de Madrid la expedición de las medicinas, y su composición, que recetaban para la curación de los enfermos, de algunos de los cuales también consta su nombre en las recetas, así como se halla en las cédulas impagadas el tratamiento y apellido del deudor, rector que fue de la universidad de Valladolid, cuyos herederos fueron demandados, a causa de los débitos de su padre, por la acreedora María de Ayala.

El recetario se muestra así como el testimonio de la comunicación entre el médico y el enfermo, entre el enfermo y el boticario y entre el boticario y el médico. Una red de comunicación en la que podremos reconocer a alguno de los facultativos que recetaban, saber lo que recetaban y para quién o por qué lo hacían.

Pero el recetario solo contiene parte de la información que precisamos, la otra parte está en el proceso sustanciado en el tribunal de la Real Chancillería de Valladolid. De ahí la obligatoriedad de dedicar unas páginas del trabajo al pleito.

1. E. CANONICA-DE ROCHEMONTEIX. El poliglotismo en el teatro de Lope de Vega. Kassel, Edition Reichenberger, 1991, pp. 94-95.

2. Es de cita obligada la obra de F.F. PASTOR FRECHOSO. Boticas, boticarios y materia médica en Valladolid (Siglos XVI y XVII). Salamanca, Junta de Castilla y León. Consejería de Cultura y Turismo, 1993. 


\section{1. "No estava OlVidado DE la QÜENTA QUe tengo con Vuestra MERCED"}

Quien así escribía, el 4 de octubre de 1574, era el doctor Félix de Manzanedo, y lo hacía en una carta misiva que remitió al boticario Francisco de Madrid, que le habría reclamado el pago de la deuda que había contraído con él por las doscientas quince recetas que le dispensó a lo largo de más de diez años, entre 1558 y 1571. Transcurridos tres años desde el último citado, el boticario le solicitaría al doctor Manzanedo el pago de las recetas, lo que dio pie a la respuesta de este:

Y sepa Vuestra Merced que no estava olvidado de la qüenta que tengo con Vuestra Merced, que es más de lo que Vuestra Merced piensa, y en ofreciéndose oportunidad yo lo pagaré cumplidamente e lo ymbiaré con persona çierta, que cada día van deste pueblo a esa villa ${ }^{3}$.

Lo cierto es que el dinero nunca se pagó y las recetas acabaron en los tribunales, concretamente en el de la Real Audiencia y Chancillería de Valladolid ${ }^{4}$. Allí fueron presentadas por el procurador Baltasar Núñez, en nombre de María de Ayala, viuda ya de Francisco de Madrid, el 16 de mayo de 1578. Habían pasado cuatro años desde la reclamación, el boticario había fallecido y también Félix de Manzanedo, y la viuda no hizo la demanda del dinero adeudado a los herederos de este último por vía epistolar sino ante el tribunal supremo de justicia que tenía su ámbito de actuación en todas las tierras castellanas localizadas al norte del Tajo.

\section{Un PLEITO PARA COBRAR LO QUE "NO ESTAVA OLVIDADO DE LA QÜENTA" Y NO SE PAGÓ}

En efecto, fue necesario que, el 15 de mayo de 1577, Baltasar Núñez, en nombre de María de Ayala, demandara entre otros, aunque no solamente a ellos, a los herederos del doctor Félix de Manzanedo, residentes en Ciudad Rodrigo, por lo que adeudaban a su representada por las mediçinas que de la botica de mi parte se an lleuado para sus casas y criados y para sý mismos. La deuda ascendía a más de 15.000 maravedís ${ }^{5}$. A los que había que sumar los maravedís que le debían los herederos del inquisidor Reliego, los de Francisco Paniagua, los del licenciado Juan de Vargas, los de Alonso Rodríguez, los que debía Pedro de Plano, los que adeudaba Valentina de Espinosa, y, en fin, los debidos por los herederos de Álvaro

3. ARCHIVO DE LA REAL CHANCILLERÍA DE VALLADOLID (=ARCHV), Pleitos Civiles, Alonso Rodríguez (fenecidos), caja 889-3.

4. Una aproximación al archivo que custodia la documentación generada y recibida por el Tribunal de la Real Chancillería, suprimida en 1834, puede consultarse el libro de S. ARRIBAS GONZÁLEZ - A.Ma FEIJÓO CASADO. (dirs.) Guía del Archivo de la Real Chancillería de Valladolid. Valladolid, Universidad de Valladolid: Secretariado de Publicaciones e Intercambio Científico, 1998. Puede verse bibliografía relacionada con el ARCHV en http:/www.mcu.es/archivos/MC/ACV/FondosDocumentales/Bibliografia.html (Fecha de consulta: 30 de abril de 2012).

5. ARCHV, Pleitos Civiles, Alonso Rodríguez (f), caja 889-3, ff. 4r-6v. 
de Sarria. Lo que suma y monta çiento y quarenta y ocho mill e quinientos y siete maravedis $^{6} .148 .507$ maravedís no son cantidad pequeña. Cuadruplicaba el sueldo de un catedrático de Medicina de la Universidad de Alcalá, que cobraba en la época 200 ducados (35.000 maravedís) y era muy superior a las 35 libras (13.125 maravedís) que percibía en 1572 un catedrático del Estudio General de Barcelona $^{7}$. No era, además, lo único que se le debía a Francisco de Madrid, acreedor nada más y nada menos que del Hospital de Esgueva de la villa de Valladolid, que el 14 de octubre de 1569 reconocía una deuda con el boticario de 300.000 maravedís $^{8}$, que debieron satisfacerse porque no están entre los demandados por su viuda. Todo ello hace pensar que su negocio marchaba viento en popa. Negocio del que algo conocemos merced a la transcripción del inventario que se hizo de su botica en 1560, que nos proporciona el profesor Anastasio Rojo Vega9

La viuda del boticario presentó ante el tribunal vallisoletano, al que llegó su demanda por encontrarse el suyo entre los posibles casos de corte al ser María de Ayala una viuda honesta, la qüenta de las mediçinas que se llebaron para el serbiçio y casa del señor doctor Mançanedo, asentando en el balance cada una de las medicinas que salieron de la botica de su marido, Francisco de Madrid ${ }^{10}$, que, sin poder afirmarlo con rotundidad sí aventuramos que pudiera tener el negocio en la Trapería. Al menos en esa calle, próxima a la Plazuela de Carnicerías ${ }^{11}$ (hoy Plaza de la Libertad), en abril de 1544, compró a Constanza Ruiz, viuda de Antón Gutiérrez y vecina de Valladolid, unos suelos de dos casas por cien ducados ${ }^{12}$, muy posiblemente para levantar su vivienda y negocio. Un buen lugar, cercano a la Universidad y al Hospital de Esgueva, al que sirvió, y este pagó, productos de su botica.

Félix de Manzanedo, padre de los demandados, nació en 1500, en el salmantino pueblo de San Felices de los Gallegos, y murió el 25 de octubre de 1576 en Ciudad Rodrigo. Aquí residían los hijos que tuvo con Isabel de Ceínos, fallecida antes que él, a los que demandó la viuda María de Ayala, y que eran: Antonio, Leonor, Isabel, Mayor y Elena, que por su minoría de edad nombraron el 4 de junio de 1577 a Pedro de Manzanedo como curador que les tutorizara y defendiera sus intereses y hacienda ${ }^{13}$. Félix de Manzanedo acumuló una deuda de 15.717 maravedís en recetas, quizá porque su poder adquisitivo no hacía pensar al boticario que el rector pudiera morir sin saldarla. Lo cierto es que no lo hizo, aun teniendo seguros ingresos al poseer, sucesivamente, la Cátedra trienal de Instituta (1529), la trienal

6. ARCHV, Pleitos Civiles, Alonso Rodríguez (f), caja 889-3, f. 6r.

7. A. FERNÁNDEZ LUZÓN. La Universidad de Barcelona en el siglo XVI. Barcelona, Publicacions i Edicions de la Universitat de Barcelona, 2005, p. 115.

8. ARCHIVO MUNICIPAL DE VALLADOLID, Hospital de Esgueva, caja 391-16.

9. Historia de la Farmacia: una farmacia en valladolid, año 1560, en http://anastasiorojovega. com (Fecha de consulta: 9 de septiembre de 2013).

10. ARCHV, Pleitos Civiles, Alonso Rodríguez (f), caja 889-3, ff. 33r-37v.

11. J. AGAPITO Y REVILLA. Las calles de Valladolid: nomenclator histórico. Valladolid, Grupo Pinciano, 1982, p. 204.

12. ARCHV, Registro de Ejecutorias, caja 625,27.

13. ARCHV, Pleitos Civiles, Alonso Rodríguez (f), caja 889-3, ff. 12r-17r. 
de Código antigua (1530), ambas en la Facultad de Leyes de la Universidad de Valladolid; ser nombrado por Carlos V oidor de la Chancillería vallisoletana en 1536, volver a la universidad y ocupar, en 1546, la Cátedra de Prima de Leyes (donde ejerció la docencia hasta su jubilación, en 1567) y ser el rector de la Universidad de la villa del Pisuerga en los cursos académicos $1535-1536$ y $1536-1537^{14}$.

Poco después de jubilarse debió enviudar de su segunda esposa: Isabel de Ceínos, que firma la última receta el 8 de agosto de $1568^{15}$, día después del cual las cédulas serían firmadas por el propio Félix de Manzanedo y en dos ocasiones por su hija Ana de Manzanedo, fruto del matrimonio del rector con su primera mujer: Ana de Quiñones ${ }^{16}$, hija de Suero de Quiñones, con la que tuvo además a Alonso de Manzanedo y Quiñones, del que sabemos que nació en 1557 y llegó a ser Inquisidor en Barcelona y Juez de la Rota en Roma, amén de promotor de la causa de canonización de Santa Teresa de Jesús ${ }^{17}$.

Una vez viudo, con setenta años cumplidos, Félix de Manzanedo se marchó a Ciudad Rodrigo, donde sin traba alguna, se ordenó presbítero y opositó y obtuvo, nemine discrepante, una canonjía doctoral en Ciudad Rodrigo, donde quedaron huérfanos en 1576 los hijos que tuvo con Isabel de Ceínos. Ana y Alonso, los hijos nacidos de su primera esposa, Ana de Quiñones, no estaban con los menores cuando estos nombraron curador a Pedro de Manzanedo, que el 5 de junio de 1577, dio poder a Juan de Herrera, solicitador en la Chancillería, a Juan Cid y a Rodrigo de Carrión, procuradores de Causas en el tribunal vallisoletano, y a Francisco de Hares, procurador del número en la villa, para que representaran a sus tutelados en todos sus pleitos ${ }^{18}$.

No habían transcurrido dos meses cuando, el 30 de julio, el escribano de Ciudad Rodrigo Francisco de Párraga notificó a Pedro de Manzanedo, en la casa que tenía en la calle de los Gigantes de esta ciudad, la provisión de Felipe II, datada el 18 de mayo de 1577, ordenando a los herederos del doctor Manzanedo que se presentaran, o sus procuradores, en la Chancillería de Valladolid, en el plazo de quince días, a responder a la demanda que Baltasar Núñez, en nombre de María

14. Para la biografía de Félix de Manzanedo pueden consultarse: M. ALCOCER MARTÍNEZ. Historia de la Universidad de Valladolid. Expedientes de provisiones de cátedras. Valladolid, [1921], p. 147, 187, 230 y 381; ÍDEM, Historia de la Universidad de Valladolid. Bio-bibliografía de juristas notables. Valladolid, 1924, pp. 101-102; M.J. PELÁEZ. (dir. y coord.) Diccionario crítico de juristas Españoles, Portugueses y Latinoamericanos (Hispánicos, Brasileños, Quebequenses y restantes francófonos). Zaragoza-Barcelona, 2006, vol. II, pp. 43-46.

15. Véase cédula número 48 del recetario.

16. M.J. PELÁEZ. (dir. y coord.) Diccionario crítico de juristas Españoles, Portugueses y Latinoamericanos, p. 45, opina que fue la segunda mujer de Félix de Manzanedo, pero las simples datas de las recetas, sin necesidad de atender a otros datos biográficos del catedrático vallisoletano, no admiten tal opinión.

17. J. SIMÓN DÍAZ. Bibliografía de la Literatura Hispánica. Madrid, Instituto Miguel de Cervantes. CSIC, 1984, tomo XIV, p. 116; C. GONZÁLEZ GARCÍA-VALLADOLID. Datos para la Historia Biográfica de la M.L.M.N.H. y Excma. ciudad de Valladolid. Valladolid, Imprenta y Librería Nacional y Extranjera de Hijos de Rodríguez, libreros de la Universidad y del Instituto, 1894, pp. 25-26.

18. ARCHV, Pleitos Civiles, Alonso Rodríguez (f), caja 889-3, ff. 10r-11r. 
de Ayala, viuda y heredera del boticario Francisco de Madrid, había presentado en ese tribunal ${ }^{19}$.

El 10 de octubre de 1578, el presidente y oidores del tribunal vallisoletano, pronunciaron un auto, que resolvía el pleito entre María de Ayala y los hijos menores (Antonio, Leonor, Isabel, Mayor y Elena) y herederos de Félix de Manzanedo, por el que ordenaban entregar las recetas de las medicinas que encargó y no pagó el que fuera rector de la universidad vallisoletana, y que había presentado en el pleito el procurador de María de Ayala, al fraile de San Pablo de Valladolid que tuviera cargo de la botica del monasterio, para que tasara el costo de las medicinas contenidas en las recetas en el tiempo que las expendió el boticario Francisco de Madrid, para que declarara su valor y se lo pagaran a María de Ayala los herederos del doctor Manzanedo ${ }^{20}$.

El fraile que hizo la tasación fue Juan Ruiz de Santillana, que entendió que el valor de las medicinas debidas por los herederos de Félix de Manzanedo era de 11.800 maravedís, en lugar de los 15.717 maravedís demandados por la viuda del boticario Francisco de Madrid.

Año y medio después de iniciado el pleito, concretamente el 14 de noviembre de 1578, el escribano Pedro de Aranda dio testimonio de la estimación realizada por fray Juan Ruiz de Santillana. Con ello concluyó el pleito, y en el mes de diciembre la parte de María de Ayala solicitó la ejecutoria del mismo ${ }^{21}$.

\section{EL RECETARIO QUE "NO ESTAVA OLVIDADO"}

La tercera acepción de la palabra recetario que proporciona el Diccionario de la RAE, en su vigésima segunda edición, reza así: "conjunto de recetas no pagadas, puestas regularmente en un alambre por los boticarios". Solo una circunstancia separa a nuestro recetario del significado de la palabra referido: las recetas, llamadas también cédulas en el pleito, no están puestas en un alambre, que habría dañado el papel en el legajo, sino en una cuerda de cuero.

Sabemos que fueron presentadas doscientas quince recetas, pero en la actualidad se han perdido dos y sólo hay en el recetario doscientas trece, aunque sí se asentaron en la qüenta de las mediçinas que se llebaron para el serbiçio y casa del señor doctor Mançanedo, que también se presentó como prueba.

Del total de recetas que han llegado a nosotros están fechadas sesenta y nueve, es decir, el 32’39\% de las mismas. Fueron escritas entre los años 1558 y 1571, si bien la mayoría de ellas se prescribieron entre 1563 y 1567. El número de cédulas datadas, su fecha y porcentaje quedan representados en la tabla y gráfico siguientes:

19. ARCHV, Pleitos Civiles, Alonso Rodríguez (f), caja 889-3, ff. 1r-3r.

20. ARCHV, Pleitos Civiles, Alonso Rodríguez (f), caja 889-3, f. 61r.

21. ARCHV, Pleitos Civiles, Alonso Rodríguez (f), caja 889-3, f. 66r. 


\begin{tabular}{|c|c|c|}
\hline AÑO & NÚMERO DE RECETAS & PORCENTAJE \\
\hline 1558 & 1 & $1^{\prime} 44 \%$ \\
\hline 1560 & 1 & $1^{\prime} 44 \%$ \\
\hline 1563 & 10 & $14^{\prime} 49 \%$ \\
\hline 1564 & 16 & $23^{\prime} 18 \%$ \\
\hline 1565 & 2 & $2^{\prime} 89^{\prime} \%$ \\
\hline 1566 & 11 & $15^{\prime} 44 \%$ \\
\hline 1567 & 21 & $30^{\prime} 43 \%$ \\
\hline 1568 & 3 & $4^{\prime} 34 \%$ \\
\hline 1569 & 2 & $2^{\prime} 89^{\prime} \%$ \\
\hline 1570 & 1 & $1^{\prime} 44 \%$ \\
\hline 1571 & 1 & $1^{\prime} 44^{\prime} \%$ \\
\hline
\end{tabular}

\section{RECETAS FECHADAS QUE SE EXPENDIERON AL DOCTOR FÉLIX DE MANZANEDO (1558 -1571)}

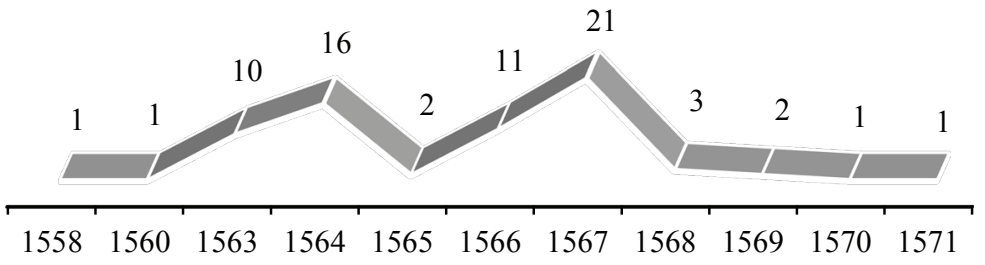

Figura 1. Recetas datadas en el recetario del boticario Francisco de Madrid

En los años que van de 1563 a 1567 se despacharon sesenta recetas, es decir, el 86 '95\% de las que llevan fecha. Es posible que ese porcentaje sea muy similar al del total de las cédulas, pero es una hipótesis, y solo podríamos decirlo con rotundidad si tuviéramos la certeza, que no tenemos, de que el orden actual de las recetas en el recetario no se ha alterado y es el mismo que tuvieron cuando fueron despachadas y ensartadas en la botica de Francisco de Madrid.

Los cinco hijos del doctor Félix de Manzanedo e Isabel de Ceínos nacieron entre 1553 y 1565 , de acuerdo a los años que dicen tener en la carta de curaduría que otorgaron en Ciudad Rodrigo en 1577, por la que sabemos que son menores de veinticinco años, momento en que se alcanzaba la mayoría de edad, y que Elena cuenta con doce años. Cinco niños: Elena, Mayor, Antonio, Leonor e Isabel, y la propia Isabel de Ceínos, la mujer del rector, serían buenos clientes del boticario. Seguramente el niño al que se alude en la receta expedida el 15 de agosto de 1567, en la que se solicita vn poco de vngüento contra rotura sea Antonio ${ }^{22}$. No es la única ocasión en que se alude a la fractura, puesto que en una receta que no lleva

22. Véase cédula número 56. 
fecha, pero que muy bien pudo expedirse con anterioridad, por el lugar que ocupa en el recetario, se pide un enplasto de suelda con suelda para vn niño quebrado ${ }^{23}$. Los niños no suelen aparecen citados en las recetas con sus nombres, sino como vna niña mala ${ }^{24}$, el niño ${ }^{25}$, vnos niños ${ }^{26}$, una niña que tiene muy gran tos ${ }^{27}$, Para la niña del señor doctor $M a<n>$ sanedo $^{28}$, para una niña chiquita mía ${ }^{29}$, para su hija ${ }^{30}$, Para vn hijo del señor doctor Mançanedo ${ }^{31}$. En una ocasión se cita a su hija Isabel, a la que se recetaron dos onzas de aceite de ajenjo (Olei absinthii 3 II) ${ }^{32}$.

No solo los niños estaban enfermos en la casa del catedrático de Prima de Leyes, también se encargan recetas para él: para el $a m o^{33}$, y para su segunda mujer, Inés de Ceínos: jarabe violado, el 19 de marzo de $1558^{34}$, y cáscaras de cidra $\mathrm{seca}^{35}$ en una fecha que no conocemos, aunque pensamos que pudo ser en 1564 o 1565 . La falta de información no nos permite saber mucho más, pero debieron los médicos de la villa del Pisuerga recetarle bastantes más medicinas de las contenidas en las recetas que conocemos, puesto que murió entre 1568 y 1570 . En 1567, el 2 de mayo, el médico le recetó una onza de un arrope hecho a base de jarabe de borrajas y endibias ${ }^{36}$. Más compleja fue la receta que se encargó Para mi señora, doña Ysabel, un día desconocido: Pulpę cassie eleose et medicaminis Hamech simplicis sin stamonea, et ycoloquyntida ana 3 F; rhabarbari eleosi 3 I77 $^{37}$ o las cuatro onzas de jarabe violado y una de aceite nardino que le recetaron otro día también desconocido ${ }^{38}$. Media onza vnguenti vniversalis le prescribieron el 11 de marzo de $1564^{39}$.

La casa no estuvo ocupada únicamente por los miembros de la familia, sino también por el personal de servicio, que si estuvieron enfermos no fueron abandonados. No lo fueron ni Pedro del Valle ${ }^{40}$, ni un criado del que solo conocemos su condición $^{41}$, ni Cristóbal Sánchez, pellejero de San Miguel $^{42}$, ni el bachiller Soto ${ }^{43}$,

\footnotetext{
23. Cédula 40 .

24. Cédula 5.

25. Cédula 138.

26. Cédula 151.

27. Cédula 155.

28. Cédulas 156, 184.

29. Cédula 161.

30. Cédula 110.

31. Cédula 192.

32. Cédula 141.

33. Cédula 92.

34. Cédula 1.

35. Cédula 173.

36. Cédula 116.

37. Cédula 117.

38. Cédula 157.

39. Cédula 193.

40. Cédulas 11, 29.

41. Cédula 18.

42. Cédulas 64, 97.

43. Cédulas 68, 71, 74, 87, 89.
} 
ni Román, del que únicamente sabemos su nombre ${ }^{44}$, ni Juan de la Casta, escudero de Isabel de Ceínos ${ }^{45}$; no quedó tampoco al amparo solo de Dios una criada del señor Mançanedo que no sabemos cómo se llamaba ${ }^{46}$, tampoco María Martínez ${ }^{47}$ ni el ama del propio doctor ${ }^{48}$. En casa del rector no solo había sirvientes, para atender los asuntos domésticos o de la administración, también había esclavos, al menos tenemos noticia de una, que tampoco fue abandonada en la enfermedad: Para la negra del doctor Mancanedo se encargó una receta al boticario Francisco de Madrid ${ }^{49}$.

El total de recetas que van firmadas asciende a 181 (84'98\%), y lo fueron bien por el propio doctor Félix de Manzanedo, que rubricó 94 (el 51'9\%), o por su segunda mujer, Isabel de Ceínos, que dejó su firma en 83 de las cédulas (45’8\%). Además de ellos dos, validaron las recetas Ana de Manzanedo, que lo hizo en dos ocasiones (1’1\%), y María de Zuñiga y Julián de Escobar, que excepcionalmente firmaron una receta cada uno (0'5\%). Muy posiblemente fuera María una mujer vinculada a la familia, aunque no sabemos con qué tipo de relación ${ }^{50}$. De Julián de Escobar solo conocemos, por la letra gótico-humanística de su firma y de la receta, que también escribe él, que es un hombre con un buen dominio de la escritura ${ }^{51}$.

La firma de las cédulas, en todos estos casos, supone el reconocimiento de que se encarga la medicina al boticario Francisco de Madrid y asimismo de que se asume la deuda de la medicina que no es pagada. Quien hace tal reconocimiento de manera más reiterada no es el doctor Manzanedo sino su mujer Isabel, que suele acompañar la firma con expresiones de reconocimiento de deuda del tipo: $Y$ póngase todo a nuestra qüenta ${ }^{52}$; Que por esta, firmada de mi nombre, lo tomaré en qüenta ${ }^{53}$, o semejantes. El doctor Manzanedo en la cédula que firma el 19 de diciembre de 1569 escribió:

Digo yo, el doctor Mançanedo, que pagaré al señor Françisco de Madrid las tress cédulas que para Pero del Ualle de su casa se han traýdo de mediçinas de su botica. Y ellas con las demás que se rreceptaren daqui adelante para el dicho Pero del Valle se pongan a mi qüenta ${ }^{54}$.

Las firmas, sin embargo, de los médicos que prescriben los medicamentos con especificación de su preparación, no tanto de su dosis y de su uso, no abundan, lamentablemente. En verdad solo un médico, Juan de Peñaranda, firma en el re-

\footnotetext{
44. Cédula 94.

45. Cédula 150 .

46. Cédulas 123, 159.

47. Cédula 165 .

48. Cédulas 163.

49. Cédula 114.

50. Cédula 4.

51. Cédula 189.

52. Cédula 7.

53. Cédula 62.

54. Cédula 29.
} 
cetario y lo hace una única vez ${ }^{55}$, aunque deja su rúbrica en un buen número de cédulas, lo cual es parlero de una relación entre el médico y la familia Manzanedo, que no es de extrañar porque este y Juan de Peñaranda eran ambos universitarios y los dos catedráticos en Valladolid. Se cita también en una receta a Pero Enríquez, también universitario y sustituto de la primera Cátedra de Medicina. Juan de Peñaranda y Pedro Enríquez son mencionados, lo que informa de su calidad, por Alfonso Rodríguez de Guevara en su obra In Pluribus ex iis quibus Galenus impugnatur ab Andrea Vesalio Bruxelensi in constructione et usu partium corporis humani, que publicó en Coimbra en $1559^{56}$.

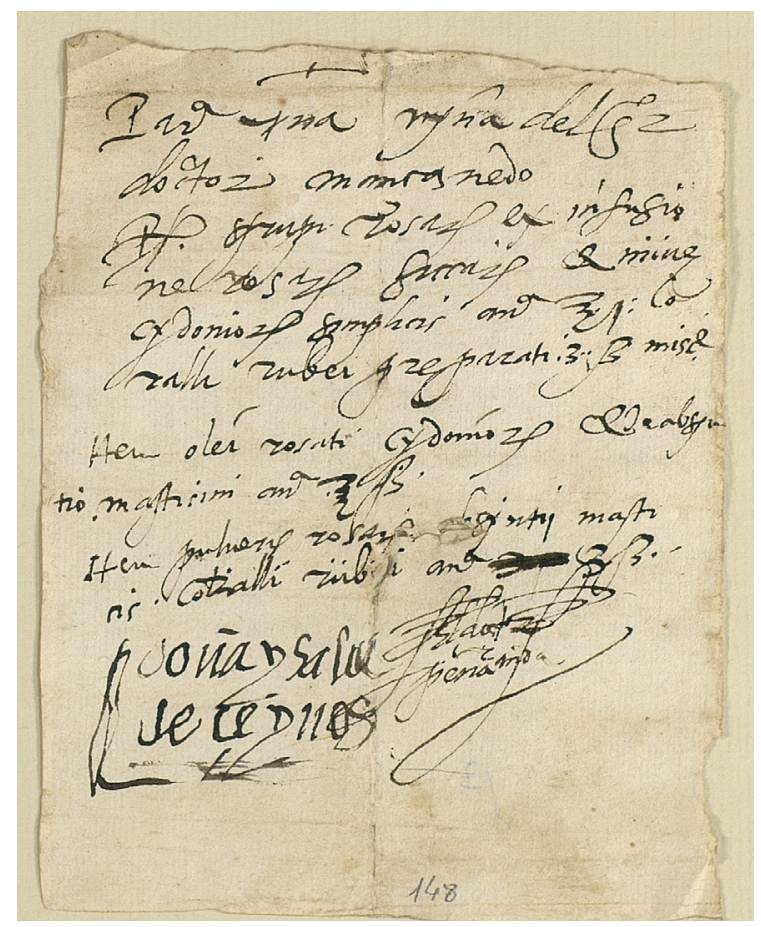

Figura 2. Firma y rúbrica del doctor Juan de Peñaranda en la receta 148, escrita por él. ARCHV, Pleitos Civiles, Alonso Rodríguez (fenecidos), caja 889-3, receta 148.

Juan de Peñaranda no se limitó a poner su firma y rúbrica en la receta número 148 , sino que la escribió además. Gracias a ello sabemos que son suyas al menos otras 19 recetas, que o bien únicamente rubricó o bien fueron escritas por él ${ }^{57}$.

55. Cédula 148.

56. Véase M. ALCOCER MARTÍNEZ. Historia de la Universidad de Valladolid. Bio-bibliografías de médicos notables. Valladolid, 1931, pp. 122-124; A. ROJO VEGA. "Los médicos vallisoletanos del siglo XVII. Status y consideración social”, en Historia y Medicina en España. Homenaje al profesor Luis S. Granjel. Valladolid, Junta de Castilla y León, 1994, pp. 127-131.

57. Cédulas 4, 6, 8, 15, 18, 33, 34, 37, 69, 101, 103, 117, 123, 145, 147, 151, 182, 184 y 187. 
Pudo ocurrir además, y estamos seguros de que así fue, que muchas otras recetas que prescribió ni las rubricó ni fueron escritas por su mano; es decir, recetaría de boca, hecho nada anormal.

Ser doctor universitario acercaría a Juan de Peñaranda al catedrático de Prima de Leyes Félix de Manzanedo, afín a la categoría del médico, que era catedrático en $1566^{58}$ y se jubiló en 1572. Anastasio Rojo le incluye entre los médicos notables de Valladolid del siglo XVI y también a Pedro Enríquez, que estamos seguros de que es quien prescribió al menos treinta del total de las recetas ${ }^{59}$, muchas de las cuales salieron de su mano, una humanística de trazado difícil, tanto como la de Peñaranda; otras las escribió el propio Félix de Manzanedo, siguiendo su dictamen, como no podía ser de otra manera. Lo que nos ha permitido reconocer al médico Pedro Enríquez es la orden que firma Manzanedo para el boticario Francisco de Madrid a quien solicita que dé otras quatro vezes el xaraue que ordenó el doctor Pero Enrríquez ${ }^{60}$ para el bachiller Soto, al servicio o próximo al catedrático de Prima de Leyes, tanto que se comprometió a sufragar la receta, aunque nunca lo hizo. El jarabe lo había prescrito Enríquez unos días antes, en otra receta que escribió de su mano ${ }^{61}$. Como ocurría con Juan de Peñaranda, es posible que muchas de las cédulas, o pocas, en cualquier caso no podemos cuantificarlas, sino solamente aventurarlo, pudo recetarlas él pero ni las escribió ni las rubricó. Pedro Enríquez se doctoró en la Facultad de Medicina de la universidad vallisoletana el 6 de mayo de $1565^{62}$.

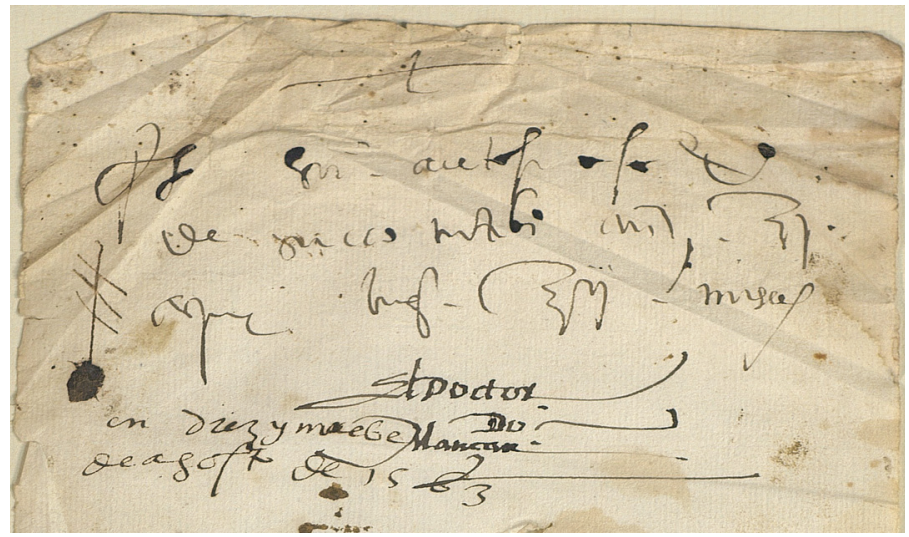

Figura 3. Letra del médico Pedro Enríquez.

ARCHV, Pleitos Civiles, Alonso Rodríguez (fenecidos), caja 889-3, receta 205.

58. M. ALCOCER MARTÍNEZ. Historia de la Universidad de Valladolid. Bio-bibliografias de médicos notables. pp. 97-98.

59. Cédulas $4,35,59,63,68,72,74,75,82,83,87,89,92,115,118,119,122,133,140,143$, $157,163,164,165,174,183,186,200,205$ y 207.

60. Cédula 71 .

61. Cédula 68.

62. M. ALCOCER MARTÍNEZ. Historia de la Universidad de Valladolid. Bio-bibliografias de médicos notables. p. 224. 
Tanto Juan de Peñaranda como Pedro Enríquez forman parte de los que Anastasio Rojo Vega llama los grandes médicos, por estar en posesión, entre otros, del título de doctor universitario. Ambos, por cronología, alcanzaron su cátedra en el reinado de Felipe II. El paso por la universidad y el ejercicio exitoso de la profesión les permitió la adquisición de un buen número de libros con lo que formar unas bibliotecas muy destacadas: Juan de Peñaranda tenía en sus anaqueles libros de medicina, en torno a una treintena, pero también de filosofía, historia, religión o literatura, entre otros. Nada, sin embargo, tenía que ver la biblioteca de Peñaranda, con 129 libros en 1569, con la de su colega Pedro Enríquez, que poseía 844 libros unos años más tarde, en 1584, y entre ellos han de contarse los de medicina, faltaría más, pero también los de filosofía y cirugía, o los de alquimia, de plantas y otros más ${ }^{63}$.

\section{4. "LAS MEDIÇINAS QUE SE LLEBARON PARA EL SERBIÇIO Y CASA DEL SEÑOR DOCTOR MANÇANEDO"}

Las medicinas que despachó el boticario Francisco de Madrid ${ }^{64}$ para los ocupantes de la casa del doctor Manzanedo y recetaron los médicos Juan de Peñaranda y Pedro Enríquez, y seguramente algún otro u otros más que desconocemos, fueron de calidades bien distintas: preparados polifármacos personales para cada uno de los enfermos y compuestos medicinales preparados de forma genérica en la botica de Francisco de Madrid o en otra de las muchas que había en la villa de Valladolid ${ }^{65}$. Aunque en la mayoría de los casos los simples y compuestos serían prescritos una vez conocida la dolencia del enfermo, para que actuaran contrariamente a las causas de la enfermedad ${ }^{66}$.

Comparando la información que contienen los repertorios de las boticas del siglo $\mathrm{XVI}^{67}$ con la contenida en las cédulas que estudiamos, hallamos unas analogías lógicas en preparados y simples. Las recetas que no pagó Manzanedo permiten

63. Véase el libro de A. ROJO VEGA. Enfermos y sanadores en la Castilla del siglo XVI. Valladolid, Universidad de Valladolid: Secretariado de Publicaciones, 1993, pp. 9-17; IDEM, "Astrología judiciaria y esfera para médicos. Valladolid 1599”, Medicina \& Historia, 1 (2010), pp. 9-12; IDEM, Ciencia y cultura en Valladolid. Estudio de las bibliotecas privadas de los siglos XVI y XVII. Valladolid: Universidad de Valladolid, 1985, pp.37-42.

64. Francisco de Madrid no está en la nómina de boticarios de Valladolid del siglo XVI que ofrece F.F. PASTOR FRECHOSO. Boticas, boticarios y materia médica en Valladolid (Siglos XVI y $X V I I$, p. 41.

65. En torno a 1565 se solicita al boticario Francisco de Madrid una onza de jarabe rosado de nueve infusiones de rosa castellana, y en la receta se hace constar: "que si no lo tiene nos haga merced de mandarlo buscar". Cédula 153.

66. Véase F.J. PUERTO SARMIENTO. "Los productos farmacéuticos de los siglos XVI y XVII”, en El botamen de la farmacia del Hospital de Simón Ruiz en Medina del Campo, Valladolid, [2005]. pp. 25-30; A. Rojo VEGA, Enfermos y sanadores en la Castilla del siglo XVI, p. 67.

67. Véase el capítulo sobre materia médica que ofrece F.F. PASTOR FRECHOSO. Boticas, boticarios y materia médica en Valladolid (Siglos XVI y XVII), pp. 59-124, y el que dedica a la Terapéutica A. ROJO VEGA. Enfermos y sanadores en la Castilla del siglo XVI, pp. 67-75. 
advertir una presencia importante de compuestos. Tiene su explicación: fueron expendidas por médicos universitarios, defensores de la ortodoxia de los textos clásicos, sobre todo de Galeno ${ }^{68}$, fuente del saber y de la formación del médico en la universidad de la Alta Edad Moderna, y para el que los preparados polifármacos eran el núcleo de la terapéutica farmacológica ${ }^{69}$, que se enriqueció en España a mediados del siglo XVI con los simples de la Materia medica de Dioscórides $^{70}$, traducida al castellano por Andrés Laguna ${ }^{71}$, y que, según el profesor Rojo Vega, fue clave en la farmacología oficial del renacimiento hispano ${ }^{72}$. Al galenismo escolasticista se añadieron asimismo multitud de simples procedentes del patrimonio farmacológico árabe y no pocas sustancias resultantes de prácticas alquímicas, aguas y aceites destilados entre ellos, y asimismo los productos llegados de Oriente y de América ${ }^{73}$, y que Laguna incorporaría a su obra ${ }^{74}$. Con esa base teórica los médicos Juan de Peñaranda y Pedro Enríquez y otros no identificados expedirían las recetas para que el boticario Francisco de Madrid elaborara el compuesto solicitado o proporcionara los simples que se le requirieran. Recetas que fueron concebidas para curar y que el paso del tiempo ha convertido en un magnífico testimonio de la terapéutica practicada "a pie de cama" en el siglo XVI. En el recetario hallamos aceites, aguas, electuarios, emplastos, infusiones, jarabes, polvos o ungüentos que fueron prescritos en ocasiones conocidas y para personas entroncadas por lazos familiares, profesionales o de servidumbre y esclavitud con el doctor Félix de Manzanedo.

En las recetas aparecen además citados teóricos como Giovanni de Vigo ("De polvos de Joanes de Vigo, media onça") ${ }^{75}$, ("secumdum Artem") ${ }^{76}$, ("julep rosado según Arte") $)^{77}$, que publicó su Practica in Arte Chirurgica copiosa en 151478; Nicolás Florentino, autor de los Sermones medicinales (cicorea de Nicolao Flo-

68. J.L. PESET. “La enseñanza de la Medicina y la Cirugía en el Antiguo Régimen”, en Historia y Medicina en España. Homenaje al profesor Luis S. Granjel. Valladolid, Junta de Castilla y León, 1994, pp. 145-159.

69. F.J. PUERTO SARMIENTO. “Los productos farmacéuticos de los siglos XVI y XVII”, p. 26.

70. J.M. VALDERAS, "Benedictus Textor y la enseñanza de la "Materia Médica» de Dioscorides”, Asclepio XLVII-1 (1995), pp. 101-122, opina que "las versiones latinas de Dioscórides en la segunda década del XVI acabaron por entronizar a éste en el centro de la terapia".

71. A. DE LAGUNA, Pedacio Dioscórides Anazarbeo, acerca de la Materia Medicinal, y de los venenos mortifèros. Traduzido de lengua Griega, en la vulgar Castellana, e illustrado con claras y substanciales Annotationes, y con las figuras de innumeras plantas exquisitas y raras, por el Doctor Andrés de Laguna. En Anuers, en casa de Iuán Latio, 1555. Edición facsímil, Madrid, 1991.

72. A. ROJO VEGA, Enfermos y sanadores en la Castilla del siglo XVI, p. 70.

73. F.J. PUERTO SARMIENTO. "Los productos farmacéuticos de los siglos XVI y XVII”, p. 27.

74. J.L. FRESQUET FEBRER. "Terapéutica y materia médica americana en la obra de Andrés Laguna (1555)”, Asclepio, XLIV-2 (1992), pp. 53-82.

75. Cédula 14.

76. Cédula 11.

77. Cédula 12.

78. L.S. GRANJEL. Cirugía Española del Renacimiento, Salamanca, Universidad de Salamanca, 1968, p. 22. 
rentino, 3 II) ${ }^{79}$; o los árabes Albucrei Rasis filii Zachariae (“Ceræ quod simplicis fiat cerotum ad modum filii Zacharie") ${ }^{80}$, ("Emplasti filii Zacharie 3 II") $)^{81}$, ("Emplastri filii Zacharię 3 II") $)^{82}$, ("Emplasti Rrasis partes duas") ${ }^{83}$, cuya Opera parva tradujo Gerardo de Cremona en el Toledo del siglo XII; Mesue, Yahiah Hamec, conocido como Johannes Mesue, cuya Confectio medicaminis, es citada en diversas ocasiones: ("Confectionis medicaminis Hamec simplicis Z I") (44 $^{4}$ ("Pulpe cassie eleosę et medicaminis Hamech simplicis sin stamonea") ${ }^{85}$, ("Confectio medicaminis Amech 3 IIII") ${ }^{86}$; y, en fin, Alí Ibnal-Abbás al-Mayusí, conocido como Haly Abbás ("diarrhodonis Abbatis") 87.

No son pocas las veces en que los médicos ordenan al boticario que mezcle diferentes productos, para lo que emplean el término "misce" 88 . Indicativo, por lo demás, de que la confección del compuesto está determinada por una decisión suya. En las cédulas se resuelve también que se hagan pociones, bolas o píldoras, que se "muela gruesamente" 89 , se administre con jeringuilla ("me mand[e] prestar vna jeringa muy pequena") 90 , se tome el medicamento varios días ("An de dar de este jaraue todos tres días junto") $)^{91}$ ("Dese tres mañanas") ${ }^{92}$, se tome una determinada cantidad ("Del coçimiento tome XII onças y de acettus, II; y benedicta, media onça. Désele vnos tragos de agua de anís caliente vn poco antes") ${ }^{93}$, o se ponga en un lugar concreto ("agua estilada de miel rrosada para echar en el ojo") ${ }^{94}$ y para una dolencia específica ("azeite de almendras dulçes fresca, qu'es para el pecho")95; o se pide que el producto sea de calidad o esté fresco ("que la triaca sea de la muy buena"96, "azeite de almendras dulzes que sea fresquísimo") 97, o con

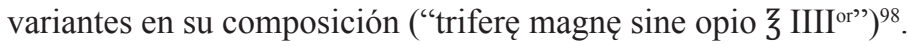

79. Cédula 10. Nicolás Florentino y Mesue son los autores más citados en la farmacopea del siglo XVI, llegando en algunos casos a representar porcentajes que sobrepasan en $75 \%$. Véase G. FOLH JOU. Medicamentos empleados por los árabes y su influencia en la Farmacia de Occidente, en especial española, desde el siglo XVI, en “América y la España del siglo XVI. I”: Madrid, CSIC. Instituto Fernández de Oviedo, 1982, pp. 233-252, especialmente p. 241.

80. Cédula 14.

81. Cédula 164.

82. Cédula 170 .

83. Cédula 209.

84. Cédula 4

85. Cédula 117.

86. Cédula 195.

87. Cédula 139.

88. Cédulas 8, 9, 26, 48, 50, 58, 59, 63, 64, 69, 94, 97, 107, 112, 116, 119, 139, 140, 148, 149, $150,164,166,177,183,186,187,192$,

89. Cédula 15.

90. Cédula 80.

91. Cédula 107.

92. Cédula 140.

93. Cédula 16.

94. Cédula 85.

95. Cédula 113.

96. Cédula 161.

97. Cédula 181.

98. Cédula 212. 
La variedad de simples y compuestos que encontramos en el recetario del boticario Francisco de Madrid es amplia. Ofrecemos a continuación una relación de los mismos, ordenada de acuerdo a la clasificación propuesta en su día por el doctor Félix F. Pastor Frechoso ${ }^{99}$ :

1. Aceites: Ajenjos, Alacrán, Alcaparras, Almástiga, Almendras amargas, Almendras dulces, Aparicio, Arrayán, Bayas, "De comer", "De crecederas", Huevos, Lirios, Lombrices, Manzanilla, Mata, Membrillo, Nardino, Rosas, Violado.

2. Adherentes: Azúcar, Azúcar rosado, Miel rosada.

3. Aguas: Acederas, Achicoria, Agrimonia, Anís, Borrajas, Endibia, Escorzonera, Hinojo, Lechuga, Lengua de buey, Llanten, Lúpulo, Miel rosada, Rosada, Verdolaga.

4. Ceras: Cera, Cera blanca.

5. Cortezas: Canela, Cidra seca, Miramolano.

6. Electuarios: Benedicta, Diacatlicón, Diarrodón, Triaca de esmeraldas, Triaca magna, Trifera magna, Zumo.

7. Emplastos: Contrarrotura, Diamorón, Diapalma, Diaquilón, Filii Zacharie, Geminis, Madurativo, Meliloto.

8. Enjundias: Ánade, Gallina, Ganso.

9. Flores, frutos, hierbas, raíces y semillas: Acedera, Acíbar, Agárico, Ajenjo, Almástiga, Anís, Assafétida, Bayas, Calabaza, China, Cidra, Ciruela, Clavo, Coloquíntida, Comino, Culantrillo de pozo, Doradilla, Endibia, Eneldo, Espica, Hinojo, Lengua de buey, Malvavisco, Manus Christi, Manzanilla, Menta, Rosas secas, Ruibarbo, Verdolaga, Zarzaparrilla.

10. Gomas: Trementina.

11. Harinas: Altramuz, Cebada.

12. Jarabes: Acetoso simple, Achicoria, Adormideras, Aromático, Borrajas, Culantrillo, Culantrillo de pozo, De dos raíces, De cinco raíces, Endibia, Fumaria, Granada, Laca, Lengua de buey, Limón, Membrillo, Miva de membrillos, Mirtino, Oximiel, Rosado, Rosa castellana, Rosa pérsica, Rosa seca, Verdolaga, Violado.

13. Lamedores: Lamedor, Lamedor violado.

14. Píldoras: Áureas, Lucis maioris.

15. Polvos: Almástiga, Arrayán, Diarrodón, Esquinanto, Juan de Vigo, Litargirio, Manzanilla, Mirtino, Perla, Rosa.

16. Preparados: Aljófar, Coral, Coral rojo.

17. Pulpas: Caña fístula, Ruibarbo.

18. Tabletas: Diarrodón, Manus Christi.

19. Ungüentos: Basilicón, Blanco, Litargirio, Resuntivo, Rosado, Rubio, Universal.

20. Vinagres: Rosado.

99. F.F. PASTOR FRECHOSO. Boticas, boticarios y materia médica en Valladolid (Siglos XVI y XVII, pp. 110-124. 
21. Vinos: Blanco.

22. Zumos: Achicoria, Borrajas, Ciruela, Endibia, Granada, Limón.

La relación anterior nos permite saber que los preparados más frecuentemente prescritos son el aceite rosado (12’20\%); los jarabes violado (10’32\%), rosado (7,51\%) y el de borrajas (7,04\%); el agua también de borrajas (7,04\%), la pulpa de canela $(7,04 \%)$ y el ungüento basilicón $(5,16 \%)$; y junto a ellos destaca la prescripción de un simple como el ruibarbo $\left(5^{\prime}, 63 \%\right)$.

La composición de los preparados de las cédulas del recetario que transcribimos en el Apéndice Documental facilitará la identificación de las enfermedades que pudieron tratarse con ellos y con los simples. Por lo que en las cédulas se escribe, sabemos que en una ocasión se recetaron tres onzas de aceite de almendras dulces para el pecho ${ }^{100}$ y en otras dos se prescribieron lamedores también para el pecho ${ }^{101}$. Roturas, fiebres, catarros, diarreas y otros padecimientos de los ocupantes de la casa de Félix de Manzanedo serían combatidas y a veces rendidas (otras no) con tabletas, ungüentos, aceites, jarabes y otros de los muchos remedios medicinales contenidos en las recetas que el rector nunca pagó.

\section{APÉNDICE DOCUMENTAL:}

El ReCETARio de Francisco de MAdrid (1558-1571)

1

$\S$ De xarabe violado, quatro onças. Para la muger del doctor Mançanedo.

$\S$ Asyéntese a la qüenta del dicho doctor.

Fecha en Valladolid, a XIX de março, 1558 años.

El doctor Maçanedo (rúbrica).

2

Señor Françisco de Madrid: mande dar al que esta lleua dos onzas de vngüento basalicón.

Doña Ana de Mancanedo (rúbrica).

3

Dos onças de açeyte de Aparicio.

Mançanedo (rúbrica).

4

$\mathrm{R}^{102}$. Confectionis medicaminis Hamec simplicis $3^{103} \mathrm{I}$, medullę cassie fistule extractę persetam $3^{104}$ VI. Cum sacharo fiant buccellę (rúbrica).

Doña María de Zvniga (rúbrica).

Para su hija del señor doctor Manzanedo.

100. Cédula 113

101. Cédulas $155,175$.

102. R] signo para abreviar Recipe.

103. 3] signo para abreviar onza.

104. 3] signo para abreviar dragma. 


\section{5}

Señor Françisco de Madrid: supplico a vuestra merçed, porque mi padre no está en la villa y tenemos vna niña mala, dar al que esta lleua dos onzas de azeite de Aparizio.

Que por esta, firmada de mi nombre, le serán pagadas.

Doña Ana de Mançanedo (rúbrica).

\section{6}

Para el señor Valle. A cuenta del señor doctor Mancanedo.

A 18 de deciembre, 1569.

R. Pulpę cassie electuarium 3 I et $\mathrm{F}^{105}$; pulueris diarhodonis $\ni^{106} \mathrm{~F}$. Fiant boli cum sacharo (rúbrica).

\section{7}

El señor doctor Manzanedo.

Señor Madrid: mande dar al que esta le diere dos honzas de vngüente blanco y vna de vngüente rosado y dos de vngüento letargilio.

Y póngase todo a nuestra qüenta.

Fecha en Valladolid, a veinte y dos días de abril, 1563 años.

Doña Ysabel de Çeýnos (rúbrica) ${ }^{107}$.

\section{8}

R. Jarabe rosado solatino de 9 infusiones, cynco onças; agua de lengua de buey, medya onça. Misce (rúbrica).

Mançanedo (rúbrica).

\section{9}

R. Sirupi cithoneorum et postulacę ana 3 III. Misce.

El doctor Mançanedo (rúbrica).

En casa de Françisco de Madrid.

10

Para en casa del señor doctor Manzanedo, a XXIX de henero de 1570.

$\S$ Zarçaparrilla, media onza; agrimonia, XI.

$\S$ Ytem xarabe de dos rraýzes sinple Z IIII; de cicorea de Nicolao Florentino, Z II.

$\S$ Ytem vn cocimiento de rraýzes de beorsonera y de lengua de buey y anís.

Yten vna onca de tabletas de diarodón duplicato reubárbaro.

\section{1}

R. Corticum myrobalanorum, citrinorum et chebulorum ana 3 I F; decostum in aqua plantagini secumdum Artem atque expressum, in quo dissolue rhabarbari optimi, 3 I. Et fiat potio.

Item electarii diarhodonis dupplicato rhabarbari $3 \mathrm{~F}$.

Es para el señor Pero del Valle, en casa del señor doctor Manzanedo.

El doctor Mançanedo (rúbrica).

105. F] signo para abreviar semis.

106. Э] signo para abreviar escrúpulo.

107. Doña Ysabel de Çeýnos (rúbrica)] en el espacio en blanco de la receta se escribió, en sentido vertical, en la Chancillería: Ay CC XV (sic) çédulas. 
12

En $v^{108}$ quartillo de vino blanco se echen vnos cogollos de axenxos pónticos.

Item se haga ${ }^{109}$ media libra de julep rosado según Arte sobre el agua dorada que lleuarán, y al fin se aromatice con vn poluo de diarhodón.

$<$ El vino blanco se lleua de acá $>$.

Item media onza de China muy escogida.

El doctor Mançanedo (rúbrica).

13

R. Emplasti diapalme quod suficiat, extendatur ad istam formam.

Mançanedo (rúbrica).

14

Casa de Françisco de Madrid.

De polvos de Joanes de Vigo, media onça.

De vngüento blanco, dos onças.

El doctor Mançanedo (rúbrica).

15

Para vna nyña del señor doctor Mançanedo.

R. Ruybarbo muy escogido, vna dra[g]ma. Muélase.

Item agua de cichoria y verdolagas, de cada vna dos onças.

El doctor Mançanedo (rúbrica).

16

Con ${ }^{110}$ cocimiento de anís, cominos, ynojo, y doblada cantidad de flor de manzanilla y açeite de mançanilla y eneldo y benedicta, se eche luego vna meleçina.

Del coçimiento tome XII onças y de acettus, II; y benedicta, media onça.

Désele vnos tragos de agua de anís caliente vn poco antes.

Para casa del doctor Manzanero (sic).

17

Señor Madrid: dará vna onza de azeyte de mançanilla y otra de bayas y otra de eneldo y otra de dialtea y otra de triaca.

Para en casa del doctor Mançanedo, en 18 de henero, 71.

18

Para vn criado del señor dotor Mançanedo.

R. Pulpę cassię 3 I et F, pulueris dracchodi 3 F. Fiant boli cum sacharo.

Item aquę buglosi $\zeta \mathrm{V}$.

(rúbrica).

108. vn] escrito sobre medio.

109. se haga] precede tachado se traiga.

110. Con] preceden anotaciones con textos de derecho: [......] restitutione expoliatorum comuniter recentus, secundum Coba[rrubias], in Regula pecatum, $2^{\mathrm{a}}$ parte.

$4^{\mathrm{a}}$ causa indiçendi belum est quando sit. 
19

R. Emplasti geminis quod suficiat, extendatur ad istam formam.

Mançanedo (rúbrica).

20

Vngüento basilicón, vna onça.

Doctor Mançanedo (rúbrica).

21

De en casa de Madrid, quatro onças de azeite rrosado.

El doctor Mançanedo (rúbrica).

22

R. Emplasti maturatiui tomuris (sic) 3 IIII.

El doctor Mançanedo (rúbrica).

23

De en casa de Madrid.

Quatro onzas de azeite rrosado

Doctor Mançanedo (rúbrica).

\section{4}

R. Vnguenti rubei de bollo ३ II.

El doctor Mançanedo (rúbrica).

25

De casa del señor Françisco de Madrid.

Dos onças de vaselicón y tres de azeyte rrosado.

El doctor Mançanedo (rúbrica).

\section{6}

Para vna niña del señor doctor Mançanedo.

R. Jarabe rosado de 9 infusiones 3 II F.

Agua de uerdolagas 3 F. Misce.

Mançanedo (rúbrica).

27

Madrid.

Azeyte rrosado, tres onças.

Doctor Mançanedo (rúbrica).

\section{8}

Dos onzas de vngüento basilicón.

Doctor Mançanedo (rúbrica).

\section{9}

Digo yo, el doctor Mançanedo, que pagaré al señor Françisco de Madrid las tress cédulas que para Pero del Ualle de su casa se han traýdo de mediçinas de su botica. Y ellas 
con las demás que se rreceptaren daquí adelante para el dicho Pero del Valle se pongan a mi qüenta.

Hecha en Valladolid, a diez y nueve de dizienbre de 1569, digo de mill y quinientos y sesenta y nueve años.

El dottor Mançanedo (rúbrica).

30

Françisco de Madrid.

De aceyte rosado, tres onzas; de trementina, dos onzas.

El doctor Mançanedo (rúbrica).

\section{1}

De azeyte rosado, tress onças.

D. Mançanedo (rúbrica).

32

De azeyte rosado, dos onças.

De casa de Françisco de Madrid.

El doctor Mançanedo (rúbrica).

33

Para vna nyña del señor dotor Mançanedo.

R. Syrupi rosacei solutiui ex rosis persicis 3 IIII.

Sea de lo de ogaño y de lo que se hiço sobre çumo.

Sean tres y media del jarabe y media de agua de ynojo.

Delo el señor Françisco de Madrid de su mano (rúbrica).

34

Para vna nyña del señor dotor Mançanedo, maio, 12, 1569.

R. Syrupi rosarum et de succo borraginis ana 3 IIII.

Item aquarum buglosi, foeniculi ana 3 VI (rúbrica).

Los jarabes por sý y las aguas por sý.

El doctor Mançanedo (rúbrica).

35

R. Rhabarbari electi infussi et expresi Э IIII ${ }^{\text {or }}$, sirupi rosarum ex 9 infusionibus 3 IIII ${ }^{\text {or }}$ F. Cum aqua fiat potus.

El doctor Mançanedo (rúbrica).

36

De jaraue violado de cassa de Françisco de Madrid, tres onças.

El doctor Mançanedo (rúbrica).

37

R. Agarici ligati et expressi in aqua fœniculi 3 F, sirupi rosacei solutiui ex 9 infusionibus 3 II et F. Fiat potus.

Para vna nyña del señor dotor Mançanedo (rúbrica).

El doctor Mançanedo (rúbrica). 
38

De agua de achicoria, seis onças.

De açucar rosado, quatro onças.

El doctor Mançanedo (rúbrica).

Julio, 1569.

39

De ruybarbo que sea muy bueno, pesso de medio real.

El doctor Mançanedo (rúbrica).

40

Contra ruptura.

Vn enplasto de suelda con suelda para vn niño quebrado.

El doctor Mançanedo (rúbrica).

41

De xarabe de dormideras, onça y media.

El doctor Mançanedo (rúbrica).

42

Vna onça de xaraue de culantrillo de pozo.

El doctor Mançanedo (rúbrica).

43

$\S$ Vna onça de coral y aljófar.

El doctor Mançanedo (rúbrica).

44

Manden dar al que la presente diere tres manadas de culantrillo de pozo.

El doctor Mançanedo (rúbrica).

\section{5}

De assafétida, media onça.

El doctor Mançanedo (rúbrica).

46

Vna manada de culantrillo de poço.

El doctor Mançanedo (rúbrica).

47

Media libra de raízes de lengua buey, las más frescas que aya; otra bebida como la de ayer.

El doctor Mançanedo (rúbrica).

48

R. Olei rosati, pulueris litargirii et cere albe ana 3 II. Misce

Doña Ysauel de Çeýnos (rúbrica).

$\mathrm{En}^{111} 8$ de agosto, 1568.

111. En] precede tachado Para 
49

R. Agua de escorzonera y buglossa, de cada vna diez onzas; jaraue de culantrillo y borrajas, de cada vno vna onza. Dese vn heruor y añádase, apartado del fuego, coral y aljófar, de cada vno media drachma.

El doctor Mançanedo (rúbrica).

50

R. Olei rosati, pulueris litargiri et cere ana 3 I F. Misce et fiat vngüentum.

Doña Ysavel de Ceýnos (rúbrica).

51

Señor Françisco de Madrid: mande vuestra merced dar al que la presente diere o[c]ho onzas de miel rosado y vna onza de vngüento basilicón.

$\mathrm{Fe}[\mathrm{c}] \mathrm{ha}$ en Valladolid, oy, juebes, a bey[n]te y o[c]ho de henero.

Doña Ysabel de Çeýnos (rúbrica).

52

Señor Françisco de Madrid: mande dar al que esa diere media onça de almástica y vna onça de açeyte de mançanilla.

Fecha en Valladolid, oy, biernes, a 2 de henero.

Doña Ysabel de Çeýnos (rúbrica).

53

R. Sirup rosarum persitarum ex 9 infusionibus $3 \mathrm{~V}$, aque buglose quod suficiat ad disoluendum.

Doña Ysabel de Çeýnos (rúbrica).

\section{4}

Doss onças de culantrillo de pozo de casa de Françisco de Madrid.

El doctor Mançanedo (rúbrica).

55

Para Sánchez, pellegero.

Rhabarbari drachma I, infundatur per noctem in aqua cicoree et expresioni adde sirupi rosarum persitarum ex 9 infusionibus $3 \mathrm{IIII}^{\text {or }}$, pro potu.

Doña Ysabel de Çeýnos (rúbrica).

56

$<$ Para en casa del señor doctor Mancanedo, a 15 de a(u)gosto, 1567>.

Señor Madrid: mande dar al que la presente le diere quatro onças de aceyte de arrayán y vnos poluos de rosa y otros poluos de arrayán. Y póngase a mi qüenta.

Fecha en Valladolid, a 15 de agosto de 1567 años.

Doña Ysabel de Çeýnos (rúbrica).

Yo he menester para vn niño vn poco de vngüento contra rotura, y mandan los médicos que sea muy fresco, y si lo vuiere déseme vn poco. Y todo se ponga a mi qüenta.

Doña Ysabel de Çeýnos (rúbrica). 
57

Señor Françisco de Madrid: mande dar al que la presente le da dos onças de açeite de arrayán y dos onças de poluos de arrayán y dos onças de poluos de rosas y dos onças de poluos de mançanilla, y uengan bien molidos los de mançanilla. Y póngase todo a mi qüenta.

Fecha en Valladolid, a 18 de agosto de $1567^{112}$.

Doña Ysabel de Çeýnos (rúbrica).

Iten diachilis Marci 3 I.

\section{8}

R. Pulueris rosarum et camomille ana 3 II F; pulueris mirthillorum 3 I. Misce.

El doctor Mançanedo (rúbrica).

59

R. Sirupi rosati et endiuię ana Z I, aquę endiuię ३ II. Misce.

El doctor Mançanedo (rúbrica).

Item pulueris rosarum et mirtillorum ana $3 \mathrm{~F}$.

(signo indicativo de que la receta se expendió en cuatro ocasiones)

\section{0}

Señor Françisco de Madrit: mande dar al que esta lleba ocho manadicas de doradilla. I asiéntese a mi cuenta.

Fecha en Valladolit, postrero deste mes.

Doña Ysabel de Çeýnos (rúbrica).

\section{1}

Señor Françisco de Madrid: mande vuestra merced dar a ese paje vna onça de arin $<\mathrm{a}>$ de altramuçes, tres de arina de çebada y dos onças de <aceyte de> (de) axenxos y dos de almendras amargas.

Yten de la votica vna onça de flor de mançanilla y media de polbos de esquinanto.

Doña Ysauel de Çeýnos (rúbrica).

\section{2}

Señor Madrid: dará vuestra merced al que esta le diere veynte y quatro onzas de azeyte rrosada. Que por esta, firmada de mi nombre, lo tomaré en qüenta.

Fecho a 15 de otubre de I mill D LX VII años.

Doña Ysabel de Çeýnos (rúbrica).

63

R. Sirupi borraginis et de succo intibi ana $\xi$ I, aquę buglose $\xi$ II. Misce.

El doctor Mançanedo (rúbrica).

(signo indicativo de que la receta se expendió en once ocasiones).

64

Para Christóbal Sánchez.

Sirupi acetosi simplici et endiuie ana 3 I, aque endiuie 3 II. Misce.

Christóbal Sánchez, pellegero a San Miguel.

112. 1567] precede tachado 1577 
Doña Ysabel de Çeýnos (rúbrica).

(signo indicativo de que la receta se expendió en tres ocasiones).

65

Señor Madid (sic): mandará dar quatro onças de lamedores. Que por esta firmada lo tomaré en qüenta.

Doña Ysabel de Çeýnos (rúbrica).

66

Señor Madrid: mande vuestra merced al que esta le diere onza y media de azeite de mançanilla y vna onza de miel rrosada. Que por esta, firmada de mi nombre, lo tomaré en qüenta.

Fecha en Valladolid, a 23 de otubre de 1567 años.

Doña Ysabel de Çeýnos (rúbrica).

67

Señor Madrid: dará vuestra merced al que esta le diere onza y media basalicón. Que por esta, firmada de mi nombre, lo rreszebiré en qüenta.

Fecha en Valladolid, a XX VII de otubre de 1567 años.

Doña Ysabel de Çeýnos (rúbrica).

\section{8}

Para el bachiller Soto.

R. De massa pilularum aurearum et lucis maioris ana $3 \mathrm{~F}$, formentur $\mathrm{V}$ et deaurentur.

El doctor Mançanedo (rúbrica).

69

Para vna nyña del señor dotor Mançanedo.

R. Jarabe de granadas y de çumo de endrina, de cada vna onça; agua de crecederas y verdolagas, de cada vna dos onças. Misce.

Doña Ysabel de Çeýnos (rúbrica).

70

Dos onças de vngüento basilicón.

El doctor Mançanedo (rúbrica).

71

Para el bachiller Soto.

Mandará vuestra merced darle otras quatro vezes el xaraue que ordenó el doctor Pero Enrríquez, que está firmado de mi mano.

El doctor Mançanedo (rúbrica).

72

Señor: mande dar al que la presente dará dos onças de ung[ü]ento blanco y vna de basilicón.

Doña Ysabel de Çeýnos (rúbrica). 
73

Para en casa del(l) señor doctor Mancanedo den media onza de acíuar, y benga muy molida. De Çeýnos (rúbrica).

\section{4}

Para el bachiller Soto otro xarafe (sic) como el de ayer, y mañana otro tanto, por manera que sean tress xarafes.

El doctor Mançanedo (rúbrica).

\section{5}

R. Unguenti resumptiui crecentis $3 \mathrm{I}$.

El doctor Mançanedo (rúbrica).

\section{6}

Mande dar vna onça de aceyte de anjenjos.

Doña Ysabel de Çeýnos (rúbrica).

77

De xaraue violado, onça y media.

El doctor Mançanedo (rúbrica).

\section{8}

Dos onças de yngüento blanco.

Doña Ysabel de Çeýnos (rúbrica).

79

Mande dar a ese paje quatro onzas de flor de mancanilla.

Doña Ysabel de Çeýnos (rúbrica).

80

Señor Françisco de Madrid: mande dar ${ }^{113}$ a ese paje tres onzas de azeyte uiolado; y me mand[e] prestar vna jeringa muy pequena, que luego se le bolberá.

Doña Ysabel de Çeýnos (rúbrica).

\section{1}

Señor: mande dar vna onça de aceyte de vebos y vna onza de açeyte de menbrillos.

Doña Ysabel de Çeýnos (rúbrica).

\section{2}

R. Pulpę cassie ffistule 3 I. Fiant boli cum sacharo.

Téngase para esta tarde, a las quatro.

Doña Ysabel de Çeýnos (rúbrica).

83

Para el bachiller Soto.

Otro xarafe como los tress, y serán por todos quatro.

El doctor Mançanedo (rúbrica).

113. dar] sigue tachado vuestra merced. 


\section{4}

De vngüento vlanco, vna onza; y otra onza de vassalicón y vna onza de pepitas de calabaça. Doña Ysabel de Çeýnos (rúbrica).

\section{5}

De agua estilada ${ }^{114}$ de miel rrosa $<$ da $>$ para echar en el ojo doss onças.

El doctor Mançanedo (rúbrica).

\section{6}

Señor Françisco de Madrid: mande dar al que la presente dará dos onças de jaraue violado y dos onças de ygüento rosado.

Fecha oy, viernes, a beynte y sey[s] de setienbre de 1567.

Doña Ysabel de Çeýnos (rúbrica).

87

Para el bachiller Soto.

R. Sirupe rosati et borraginis ana Z I; aquę foeniculi Z II.

El doctor Mançanedo (rúbrica).

(signo indicativo de que la receta se expendió en ocho ocasiones).

\section{8}

Señor: mande dar al que la presente dar[á] sey[s] oncas de aceyte rosado.

Fecha a diez de otubre de 1567.

Doña Ysabel de Çeýnos (rúbrica).

\section{9}

Para el bachiller Soto.

R. Massę pilularum aurearum et lucis ana $3 \mathrm{~F}$, formentur 5 cum aqua foeniculi et de anisi.

El doctor Mançanedo (rúbrica).

\section{0}

Señor Madrid: dará vuestra merced al que esta le diere doze onzas de azeyte rrosada. Que por esta, firmada de mi nombre, se rreszebirán en qüenta.

Fecha en Balladolid, a 16 de otubre de 1567 años.

Y más media onza de vasalicón.

Fecha ut supra.

Doña Ysabel de Çeýnos (rúbrica).

91

Señor: mande vuestra merced dar al que la presente dará libra y media de aceyte rosado.

$\mathrm{Fe}[\mathrm{c}]$ ha oy, biernes, a diez de otubre de $\mathrm{e}^{115} 1567$.

Doña Ysabel de Çeýnos (rúbrica).

Fue la libra de diez y seis honças.

114. De agua estilada] precede tachado De agua de.

115. de] sigue tachado mill. 


\section{2}

Para el amo.

R. Pulpę cassie ffistule 弓 I F. Fiant boli cum sacharo.

El doctor Mançanedo (rúbrica).

\section{3}

Señor Françisco de Madrid: mande vuestra merced dar a ese paje tres onzas de aceyte rosado. Doña Ysabel de Çeýnos (rúbrica).

\section{4}

Para Román.

Olei camomille et rosarum et lumbricorum ana 3 I. Misce.

Doña Ysabel de Çeýnos (rúbrica).

\section{5}

Mande dar vna onza de azeyte de almendras dulces ${ }^{116}$ y otra de aceyte de mancanilla. Doña Ysabel de Çeýnos (rúbrica).

\section{6}

Señor Françisco de Madrid: mande dar por esta my (sic) firmada vna onca de yngüento rosado. Fecha a 15 del mes de setienbre de mill i quinientos i sesenta i siete.

Doña Ysabel de Çeýnos (rúbrica).

\section{7}

Para Christóbal Sánchez, pellegero.

Sirupe papaueris $\zeta$ I, aque lactuce $\zeta$ F. Misce.

El doctor Mançanedo (rúbrica).

\section{8}

$\S$ Señor Françisco de Madrid: mande dar al que la presente le diere dos onças de jarabe biolado y media onça de pepitas de calabaça. Y asiéntese a mi qüenta, que por esta, firmada de mi nombre, lo pagaré todo.

Fecha en Valladolid, a 14 de setiembre de 1567 años.

Doña Ysabel de Çeýnos (rúbrica).

\section{9}

An de dar a ese paje dos oncas de azeyte rosado ${ }^{117}$.

El doctor Mançanedo (rúbrica).

\section{0}

Señor Madrid: suplico a vuestra merced mande dar dos onças de azeyte violado. Y póngase a mi qüenta. Que por esta, firmada de mi nombre, lo rresçiviré en qüenta.

Fecha en Valladolid, a 11 de septiembre de 1567 años.

Doña Ysabel de Çeýnos (rúbrica).

116. dulces] precede tachado amar.

117. rosado] sigue tachada frase ilegible. 
101

Para vna nyña del señor dotor Mançanedo.

R. Rhabarbari electi 3 I, infundatur in aque acetose et portulace.

Item tres onças del jarabe rosado de 9 infusiones.

Doña Ysabel de Ceýnos (rúbrica).

102

An de dar a este moco tres oncas de azeyte rosada y media de vinagre rosado.

Doña Ysabel de Ceýnos (rúbrica).

103

R. Olei de absyntio 3 II.

Item pulueris aloes, seminis sancti, seminis portulace acetose, coralli rubei ana $3 \mathrm{~F}$.

Item aquę portulace 3 III.

Item seminis citri 3 I.

El doctor Mançanedo (rúbrica).

\section{4}

El agua que aora trajeron de allá para desacar la purga se nos vertió, por eso ynbíeseme otra tanta.

Doña Ysabel de Ceýnos (rúbrica).

\section{5}

Para vna niña de el señor doctor Manzanedo.

Sirupe rosarum persitarum ex 9 infusionibus 3 II.

Ytem aque acetose et portulace ana $\zeta \mathrm{I}$.

Ytem rhabarbari electi Э II.

Venga el rhabarbari molido para echarse acá en infusió[n].

Doña Ysabel de Ceýnos (rúbrica).

\section{6}

R. Manus Christi perlati 3 F.

Item aque buglosę 3 IIII $\mathrm{F}$.

Doña Ysabel de Ceýnos (rúbrica).

107

R. Syrupi endivie Z I, syrupi violacei et acetosi simplicis ana Z F, aque cichorii ३ III. Misce. An de dar de este jaraue todos tres días junto.

Doña Ysabel de Ceýnos (rúbrica).

\section{8}

R. Dyaprunis simplicis 3 I, electuarii de succo rosarum 3 F.

Fiat boli cum sacharo

Doña Ysabel de Ceýnos (rúbrica).

\section{9}

Señor Françisco de Madrid: mandará dar a quien esta le diere vnos pocos de polvos de rrosas y vn poco de coral molido y vn poco de almástiga y vnos pocos de aje[n]jos. Que por esta, firmada de mi nombre, se rresçivirán en qüenta. 
Fecha en Valladolid, a XVII de septiembre de I mill D LX VII años.

Doña Ysabel de Ceýnos (rúbrica).

\section{0}

Para el señor doctor Mancanedo, para su hija, a 4 de octubre, 1567.

R. Vnguenti resumptiui $\zeta$ I.

\section{1}

Señor Françisco de Madrid: dará vuestra merced al que esta le diere dos onças de ungüento blanco. Que por esta, firmada de mi nombre, lo tomaré en qüenta.

Fecha en Valladolid, a 29 de septiembre de I mill D LX VII años.

Doña Ysabel de Ceýnos (rúbrica).

\section{2}

Para en casa del señor doctor Mancanedo, a 8 de noviembre, 1567.

R. Sirupi acetosi simplicis et endiuie ana 3 I

Aquæ buglosse 3 II. Misce.

Item sirupi papaveris, onza I; aquæ lactucæ, onza media.

(signo indicativo de que la receta se expendió en tres ocasiones).

\section{3}

Señor Françisco de Madrid: mandará dar al que esta lleva tres onças de azeite de almendras dulçes fresca, qu'es para el pecho.

Fecho en Valladolid, 23 de jullio de 1567 años.

Doña Ysabel de Ceýnos (rúbrica).

\section{4}

Para la negra del doctor Mancanedo.

R. Radices euisci cocti et cribellati 3 IIII.

Axungiæ gallinæ, anseris et anatis ana $3 \mathrm{I}$.

Olei rosarum, liliorum ana $\xi \mathrm{F}$. Ceræ quod simplicis fiat cerotum ad modum filii Zacharie.

\section{5}

R. Sirupe borraginis et de succo intibi ana 3 I.

El doctor Mançanedo (rúbrica).

Ytem agrimonię et citeradi ana $3 \mathrm{I}$.

(signo indicativo de que la receta se expendió en cinco ocasiones).

\section{6}

Para la señora del doctor Mancanedo, a 2 de mayo, 1567.

R. Serapii borragenis, intibis singulis 3 I. Misce.

\section{7}

$<$ Señor doctor Mancanedo $>$.

Para mi señora, doña Ysabel.

R. Pulpę cassie eleosę et medicaminis Hamech simplicis sin stamonea, et ycoloquyntida ana 3 F; rhabarbari eleosi 3 I. Fiant boli cum sacharo. 
118

R. Pulpę cassie ffistule 3 I, pulpe rhabarbari simplicis, citri et simplicis portulace ana $Э$ I. Fiant boli cum sacharo.

El doctor Mançanedo (rúbrica).

119

R. Pulpę cassie ffistule 3 X. Fiant boli cum sacharo.

Item pulpe rhabarbari simplicis, portulace et simplicis acetose et coraline ana Э I. Misce Item aquę portulacę 3 II.

Para casa del señor doctor Mançanedo.

120

Señor Françisco de Madrid: mande dar al que la presente lleba dos onças de jarabe de culantrillo de poço.

Fecha en Baladolid, a 24 de avril del año de 1567.

Doña Ysabel de Çeýnos (rúbrica).

121

R. Emplasti gemmis et dia[ra]dine ana quod suficiat. Extendat ad istam formam.

El doctor Mançanedo (rúbrica).

\section{2}

R. Pulpe cassie ffistule 3 X. Fiant boli cum sacharo.

Doña Ysabel de Çeýnos (rúbrica).

123

Para una criada del señor dotor Mançanedo.

R. Pulpæ casie et diacataliconis ana dragmas septem. Fiant boli ${ }^{118}$ cum sacharo (rúbrica).

\section{4}

Señor Françisco de Madrid: mándeme dar una onça de azeite de alcaparras $\mathrm{i}^{119}$ otra onca de aceite de almendras dulces i otra onca de açeite de alacrán y otra onça de aceite de bayas; i tengan estos dos aceites en una escudilla; y el de ${ }^{120}$ almendras dulces i de aceite de alcaparas, en otra. I póngase a mi cuenta.

Fecha en Valladolit, a 23 de mayo, año de 1567 años.

Doña Ysabel de Çeýnos (rúbrica).

\section{5}

Doss onças de xaraue de culantrillo de pozo.

El doctor Mançanedo (rúbrica).

126

De xaraue de culantrillo de pozo, doss onças.

El doctor Mançanedo (rúbrica).

118. boli] b escrita sobre $\mathrm{v}$.

119. i] sigue tachado açe.

120. de] precede tachada a. 


\section{7}

Sacadas en cuenta en agosto de 1566.

\section{8}

Vna onça de pulpa de caña fístola en bocados, para en casa del doctor Mançanedo ${ }^{121}$. El doctor Mançanedo (rúbrica).

\section{9}

De xaraue violado, quatro onças, para casa del doctor Mancanedo.

El doctor Mançanedo (rúbrica).

\section{0}

Señor Françisco de Madrid: supplico a vuestra merced me imbíe seis onças de azeite de comer, lo más añejo que vuiere en casa, y dos onças de azeite de alcaparras y vna onça de dialtea. Y asiéntese a mi cuenta.

Fecha en Valladolid, a 26 de otubre de 1566 años.

Doña Ysabel de Çeýnos (rúbrica).

\section{1}

Señor Françisco de Madrit: mande dar al que la presente lleua dos oncas de aceite de almendras amargas i dos oncas de aceite de alcaparas i un poco de lagrimonia i un par de manadicas de doradilla ${ }^{122}$. I póngase a mi cuenta.

Fecha en Valladolit, a $12^{123}$ de nouienure, año de 1566 años.

Doña Ysabel de Çeýnos (rúbrica).

\section{2}

$\S$ Señor Françisco de Madrid: mande vuestra merced dar quatro onças de jaraue biolado. $\mathrm{Y}$ asiéntese a mi qüenta.

Fecha en Valladolid, a 28 de nouiembre.

Doña Ysabel de Çeýnos (rúbrica).

Sacose en qüenta.

\section{3}

R. Sirupi rosacei solutiui $\zeta$ V et F; aquę buglose quod sufficiat. Fiat potus.

Doña Ysabel de Çeýnos (rúbrica).

Pasose en la qüenta.

\section{4}

R. Emplasti gemmis quod suficiat. Extendatur ad istam formam.

Doctor Mançanedo (rúbrica).

Sacadas.

\section{5}

R. Xarafe de borrajas, seys onças, para casa del doctor Mançanedo.

El doctor Mançanedo (rúbrica).

121. Mançanedo] otra mano añadió sacadas.

122. doradilla] sigue tachado Fe.

123. 12] infrascrito y tachado doçe. 
136

R. Rhabarbari optimi infussi in aqua endiuie et post suficientem moram expressi Э IIII. Syrupi rosarum persicarum ex $9^{\mathrm{a}}$ infusione 3 IIII F. Fiat potus.

El doctor Mançanedo (rúbrica).

137

R. Quatro onças de xaraue violado.

$\S$ Más otras quatro onças.

El doctor Mançanedo (rúbrica).

138

Para el niño del señor doctor Mancanedo.

R. Sirupi violati et de lacca ana 3 II.

139

R. Aque cichorii, acetose et buglose ana 3 III. Misce.

Item diarrhodonis Abbatis $3 \mathrm{~F}$.

El doctor Mançanedo (rúbrica).

140

R. Sirupe endiuie et acetose simplicis ana 3 I; aque cichorii 3 III. Misce.

El doctor Mançanedo (rúbrica).

Dese tres mañanas.

(signo indicativo de que la receta se expendió en cuatro ocasiones).

\section{1}

El señor doctor Mançanedo.

R. Olei absinthii そ II.

Para su hija doña Ysabel.

142

R. De xaraue violado y de laca, de cada vno doss onças.

El doctor Mançanedo (rúbrica).

143

R. Pulpę cassie ffistule 3 XII. Fiant boli cum sucharo.

El doctor Mançanedo (rúbrica).

144

R. Dos onças de xaraue rosado de rosas castellanas de 9 infusiones.

El doctor Mançanedo (rúbrica).

145

R. Quatro honças de lamedor violado.

El doctor Mançanedo (rúbrica). 


\section{6}

El señor docttor Manzanedo.

R. Xaraue de çumo de achicoria y de borrajas, de cada vno tres honzas.

Para vna niña.

(rúbrica).

A 27 de agosto de 1566 .

147

Para vna niña del señor doctor Mançanedo.

R. Xaraue de zumo de borrajas y de achicoria, de cada vno dos honças.

(rúbrica).

\section{8}

Para vna nyña del señor doctor Mançanedo.

R. Syrupi rosarum ex infusione rosarum siccarum et miuę cydoniroum simplicis ana $\xi$

I. Coralli rubei preparati 3 F. Misce.

Item olei rosati, cydoniorum et de absyntio, masticini ana $3 \mathrm{~F}$.

Item pulueris rosarum, absyntii, masticis, coralli rubei ana $3^{124} \mathrm{~F}$.

El doctor Peñaranda (rúbrica).

Doña Ysabel de Çeýnos (rúbrica).

\section{9}

Para Casta, $1^{\circ}$ de agosto, 1566 años.

R. Rreubarbari per noctem inffussi in aqua endiuię 3 I et F; sirupi rrosarum ex 9 inffusionibus Z III. Misce.

El doctor Mançanedo (rúbrica).

\section{0}

Para Juan de la Casta, escudero de la señora doña Isabel de Ceínos.

R. Oximelitis et sirupi endiuię ana Z I, aquę endiuię 3 II. Misce.

Postrero de agosto de 1566 años.

El doctor Mançanedo (rúbrica).

\section{1}

Para vnos niños del señor doctor Mançanedo.

R. Honza y media de pulpa de caña fístolæ. Háganse bocadillos con azúcar. (rúbrica).

\section{2}

Vna honza de aceite de almendras dulces.

El doctor Mançanedo (rúbrica).

153

Vna honça de xaraue rosado de nueve ynfusiones de rosa castellana.

Al señor Madrid: que si no lo tiene nos haga merced de mandarlo buscar.

Yten de aceite uiolado y de almendras dulçes, de cada vno vna honça.

124. 3] precede tachado Э $\mathrm{I}$. 
El doctor Mançanedo (rúbrica).

(signo indicativo de que la receta se expendió en dos ocasiones).

\section{4}

De aceite nardino, vna honza; de aceite ${ }^{125}$ de almendras, otra honça, dulçes.

De casa del señor Françisco de Madrid.

El doctor Mançanedo (rúbrica).

\section{5}

Señor Madril (sic): mande vuestra merced al que la presente lleba quatro onças de lamedores, para una niña que tiene muy gran tos.

Fecha en Balladolid, a 30 de otubre, año de 1564 años.

Doña Ysabel de Çeýnos (rúbrica).

\section{6}

$<$ Dotor Mancanedo $>$.

Para la niña del señor doctor $\mathrm{Ma}<\mathrm{n}>$ sanedo $^{126}$, en 14 de julio, 1566 .

R. Serapi violati Z II.

Y doña Ysabel Çeínos ${ }^{127}$.

\section{7}

R. Sirupi uiolati $\zeta$ IIII ${ }^{\text {or }}$.

Item oleo nardini $\zeta$ I.

Para mi señora doña Ysabel de Ceýnos, mujer del doctor Mancanedo.

158

Para la nyña del señor doctor Mansanedo, en 15 de julio, 1566.

R. Serapi violacei $\zeta$ II.

\section{9}

Para vna creada del señor doctor Mansanedo, en 14 de julio, 1566.

R. Tiriacæ smaragdi 3 II.

\section{0}

Para en casa del señor doctor Mansanedo, para vn nyño, en 27 de julio, 1566.

R. Olei spicæ Z I.

\section{1}

Señor Francisco de Madrid: mande dar vuestra merced media drama de triaca de esmeralda y una onça de azeite(te) rrosada. Y suplico a vuestra merced que la triaca sea de la muy buena porque es para una niña chiquita mía.

Fecha a 28 de agosto de 1566.

Doña Ysabel de Ceýnos (rúbrica).

125. de aceite] precede tachado de aceite.

126. $\mathrm{Ma}<\mathrm{n}>$ sanedo] infrascrito y sin tachar Mansanedo.

127. Y doña Ysabel Çeínos] siguen tachadas unas probationes pennae. 


\section{2}

Señor Madrid: mande dar vuestra merced $\operatorname{sacar}^{128}$ dos onças $<$ de azeite $>$ de almendras dulces para una niña; también me mandará dar dos onças de xarave violado. Y póngase a mi qüenta. Y a de ser esta noche en todo caso.

Fecha en Valladolid, a 15 de junio de 1564 años.

Doña Ysabel de Ceýnos (rúbrica).

Iten olei rosacei et camemali (sic) ana ろ I.

\section{3}

Casie fistule 3 IIII.

Para el ama del señor doctor Mançanedo.

\section{4}

R. Emplasti filii Zacharie Z II.

Para Antonia de Saluatierra.

Sirupi borraginis et fumarie ana $\xi$ I, aque buglose $\xi$ II. Misce.

El doctor Mançanedo (rúbrica).

R. Aque plantaginis 3 IIII ${ }^{\text {or }}$, vnguenti exicerei ana 3 I; diamoronis 3 I. Misce.

(signo indicativo de que la receta se expendió en siete ocasiones).

\section{5}

Para María Martínez.

R. Cassie fistule 3 VI F.

Ase de tomar en cana.

El señor doctor Manzanedo, en 12 de agosto, 1564.

\section{6}

Assafétida, vna onça.

El doctor Mançanedo (rúbrica).

Iten serapi bilorum et capillorum ana $3 \mathrm{I}$, oximellis simplicis onza F. Misce.

Item subpositorium ex zerę $\mathrm{n}^{\circ} 1$.

Item pulueris rosarum, mirtillorum ana $\xi \mathrm{F}$.

\section{7}

El doctor Mançanedo para vna niña.

R. Olei admigdalarum dultium 3 I.

En 30 de jullio de 1564 .

\section{8}

Señor Madrid: mande buesa merzed dar al que la presente llieba quatro onzas de xaraue uiolado.

Fecha en Valladolid, a diez y nuebe del mes de julio de mill e quinientos y sesenta y quatro años.

Doña Ysabel de Çeýnos (rúbrica).

128. sacar] precede tachado dar. 
169

Señor Madri[d]: mande vuestra merced dar quatro onças de xarave violado.

Fecha en Valladolid, a diez y ocho de julio de mill D LX IIII'.

Doña Ysabel de Çeýnos (rúbrica).

170

R. Emplastri filii Zacharię 3 II.

R. Sirupi violarum 3 IIII ${ }^{\text {or }}$.

Esto y todo lo demás que receptare el médico yo lo pagaré.

Fecho a 21 de julio, 1564.

El doctor Mançanedo (rúbrica).

(signo indicativo de que la receta se expendió en dos ocasiones).

171

R. Pulpe cassiæ 3 XII. Fiant boli [cum] sacharo.

Item aque buglose 3 IIII ${ }^{\circ}$.

El doctor Mançanedo (rúbrica).

\section{2}

Señor Madrid: dará buesa merzed dos onzas de xarabe violado.

Fecha en Valladolid, a XX de julio de mill e quinientos e sesenta e IIII $^{\circ}$ años.

Doña Ysabel de Çeýnos (rúbrica).

173

Cáscaras de cydra seca para cozer agua para la muger del doctor Mançanedo, de casa de Françisco de Madrid.

El doctor Mançanedo (rúbrica).

\section{4}

R. Pulpe cassie ffistule 3 I. Fiant boli cum sacharo.

El doctor Mançanedo (rúbrica).

\section{5}

Señor Madrid: mande vuestra merced dar dos honzas de lamedor para el pecho. Que por esta, firmada de mi nonbre, se le pagará.

Fecha a nuebe de julio de mill e quinientos e sesenta y çinco años.

Doña Ysabel de Çeýnos (rúbrica).

El doctor Mançanedo.

176

Señor Madrid: mande da[r] vuestra merced huna honza de vngüente rrosado que sea fresco y muy bueno. Que por esta se tomará en qüenta.

Fecha en Valladolid, a 26 de junio de 1565.

Doña Ysabel de Çeýnos (rúbrica).

177

R. Sirupi capillorum, veneris et de lacca ana 3 I. Misce.

Doña Ysabel de Çeýnos (rúbrica). 


\section{8}

$<$ Manus Christi $>$.

Señor Madrid: mande vuestra merced dar al que la presente lleva quatro tabletas.

Fecha en Valladolid, a primero de otubre de 1564 años.

An de ser las tablillas de las que se trajeron ayer tarde.

Doña Ysabel de Çeýnos (rúbrica).

179

Señor Françisco de Madrid: mande dar vuestra merced a esa muger quatro onças de lamedor.

Fecha a 18 de março de 1560.

Doña Ysabel de Çeýnos (rúbrica).

Señor doctor Mançanedo.

180

Señor Madrid: mande vuestra merced (d)dar tres onças de açeite rosada y media onça de vinagre rosado, para en casa del doctor Mançanedo.

Fecha en Valladolid, a 30 de setienbre, año de 1564.

Doña Ysabel de Çeýnos (rúbrica).

\section{1}

Señor Madrid: mande vuestra merced azer sacar las dos onças de azeite de almendras dulzes que sea fresquísimo porqu'es p[ar]a la nyña.

Doña Ysabel de Çeýnos (rúbrica).

\section{2}

R. Manus Christi, vna onca.

Aque rosarum 3 II (rúbrica).

Para casa del dotor Mança $<$ ne $>$ do.

\section{3}

R. Theriacę magnę et smaragdorum ana Э I.

Aquę buglosę 3 II, pulueris diamargaritoris frigidis 3 I. Misce. Fiat potus.

Doña Ysabel de Çeýnos (rúbrica).

El doctor Mançanedo.

\section{4}

Para la niña de el señor doctor Mançanedo.

R. Aquę buglosę et acetosę ana $\zeta$ VI.

Suci granatorum agradulce 3 III.

Sacaro optimi 3 VI. Fiat juleb aromatici 3 F; diamargaritoris sugati in petra rara (rúbrica).

Doña Ysabel de Çeýnos (rúbrica).

\section{5}

R. Mançanilla y rrosas secas, de cada cosa vn puño; ac[e]ite rrosado, tres onças; vinagre rosado, vna onça.

Para en casa del señor doctor Mançanedo (rúbrica). 
186

R. Sirupi borraginis 3 I F, endiuię $\xi$ F, aque cicoree $\zeta$ II. Misce.

Para casa del doctor Mançanedo (rúbrica).

\section{7 (rota)}

Para vna nyña del señor dotor Mançanedo.

R. syrupi myrthini [et] miuę simplicis cydonior[um ana] ZI; pulueris ma[rgarita]rum pręparatarum [et coralei] rubei prepara[ti ana 3 F]. Misce (rúbrica).

\section{8}

$\S$ Para en casa del doctor Mançanedo.

$\S$ Dos onças de azeyte rrosado.

$\S$ dos marcos de yngüente basalicón.

Doctor Mançanedo (rúbrica).

\section{9}

Para casa del doctor Mançanedo.

Vnos pocos de polvos de almástiga y otros pocos de polvos de rosa y polvos de raya $<$ ana 3 II >, y media onza de azeyte de almástiga. Item puluis sandaracei 3 I.

Llebolo Julián d'Escobar y firmolo de su nombre.

Julián d'Escobar (rúbrica).

\section{0}

$<$ Item corralli rrubei $\zeta$ II $>$.

Señor Madrid: mande vuestra merced dar al que la presenta lleva onça y media de caña fístola, pulpa.

Fecha en Valladolid, a 16 de junio de 1564 años.

Doña Ysabel de Çeýnos (rúbrica).

\section{1}

Señor Madrid: mande vuestra merced dar al que la presenta lleba dos onças de jarabe violado y una onça de jarabe de culantrillo de poço.

Fecha oy, viernes, a beynte y un días del mes de abril, año de 1564 años.

Doña Ysabel de Çeýnos (rúbrica).

\section{2}

$<$ Item aquę rosacei $\zeta \mathrm{I}>$.

R. Sirupi de lacca et violati ana $\zeta$ II. Misce.

Para vn hijo del señor doctor Mançanedo, a 28 de mayo, 1564.

(signo indicativo de que la receta se expendió en dos ocasiones).

\section{3}

Señor Françisco de Madrid: mande vuestra merced dar quatro onzas de azeyte violado. Fecha en Valladolid, a 11 de março de 1564 años.

El doctor Mançanedo (rúbrica).

Para la señora doña Ysabel vnguenti vniversalis 3 F. 


\section{4}

Señor Madrid: mande dar al que la presenta lleba tres onças de jarave de rrosas secas.

Fecha en Balladolid, a ue[i]nte y ocho días del mes de março, año de mil y quinientos y sese[n]ta y quatro años.

Doña Ysabel de Çeýnos (rúbrica).

195

R. Diacatholicon Z F, confectio medicaminis Amech 3 IIII, clettindi 3 III, in melancolica. Fiat potus, dulcuretur cum sirupi rosati $\xi$ et $\mathrm{F}$.

El doctor Mançanedo (rúbrica).

196

R. Sirupi borraginis et de quinque radicibus ana $\xi \mathrm{I}$, aquarum lupulorum et rosarum ana Z I F. Misce.

Doña Ysabel de Çeýnos (rúbrica).

El doctor Mançanedo.

(signo indicativo de que la receta se expendió en tres ocasiones).

197

R. Olei masticis et absinthii ana 3 I; pulueris rosarum, absinthii, menthe ana 3 F; cariophilorum, micis, moschate, spice ana $Э_{\mathrm{F}}$; çere ${ }^{129}$ quod satis. Fiat vnguentum.

$\S$ Item mive cidoniorum ex sacharo 3 III.

El doctor Mançanedo (rúbrica).

198

Señor Madrid: mande vuestra merced dar al que la presenta lleva seis onças de xarave de lengua buey.

Fecha en Valladolid, a diez y seis de dezienbre, año de mil D LX III.

Doña Ysabel de Çeýnos (rúbrica).

El doctor Mançanedo.

199

Señor Madrid: mande dar al que esta le diere vna onça de açeyte de mata. Y póngase a mi qüenta.

Fecha oy, sábado, a 18 de dezienbre, año de 1563 años.

Doña Ysabel de Çeýnos (rúbrica).

El doctor Mançanedo.

200

R. sirupi uiolati 3 III.

Para vna niña en cassa del doctor Mancanedo, en 2 de henero, 1564.

(signo indicativo de que la receta se expendió en dos ocasiones).

201

Señor Madrid: mandará dar al que esta le diere honça y media de jaraue de dormideras. Fecha en Valladolid, vltimo de agosto de mill y quinientos y sesenta y tress años.

Doña Ysabel de Çeýnos (rúbrica).

129. çere] precede tachado mast. 
202

R. Sirupi de fumoterre et borraginis ana ३ I, aquę buclosę そ II. Misce.

Mançanedo (rúbrica).

203

Vna onza de dialtea para en casa del doctor Mançanedo.

204

Señor Madrid: por esta cédula mande dar çinco días de cada día vna honza de xaraue de borrajas. Que por esta, firmada de mi nombre, yo la tomaré en qüenta.

Fecha XVII días de jullio de I mill D LX III años.

Doña Ysabel de Çeýnos (rúbrica).

205

R. Sirupe acetosi simplicis et de succo intibi ana $\xi$ I; aquę buglose $\xi$ II. Misce.

El doctor Mançanedo (rúbrica).

$<$ En diez y nuebe de agosto de $1563>$.

(signo indicativo de que la receta se expendió en tres ocasiones).

\section{6}

Señor Madrid: mande dar al que esta le diere vna honza de xarabe de borrajas.

Fecha en nueue días del mes de julio, 1563 años.

Doña Ysabel de Çeýnos (rúbrica).

207

R. Sirupe de succo limonum et de succo intibi ana 3 I, aquę buglose 3 III. Misce.

El doctor Mançanedo (rúbrica).

(signo indicativo de que la receta se expendió en ocho ocasiones).

\section{8}

R. Rhabarbari infusi et expressi in aqua intibi $\zeta$ I et F. Sirupi rosacei solutiui 3 IIII ${ }^{\text {or }}$. Fiat potus.

El doctor Mançanedo (rúbrica).

209

R. Emplasti Rrasis partes duas, mell(1)iloti partem unam. Misce, et extendatur ad istam formam.

Doña Ysabel de Çeýnos (rúbrica).

El doctor Mançanedo.

210

Doctor Mançanedo.

Señor Madrid: mande dar al que esta le diere çinco honzas de azeite rrosado y vna de vinagre rrosado.

Fecha en Valladolid, a veynte y nueue días del mes de abril de mill e quinientos y sesenta y tres años.

Doña Ys[abe]1 de Çeýnos (rúbrica).

(signo indicativo de que la receta se expendió en dos ocasiones). 


\section{1}

R. Olei rrosati et pulueris litargirii ana 3 I F; cere albe 3 X. Misce, et fiat vnguentum. El doctor Mançanedo (rúbrica).

\section{2}

$<$ Item triferę magnę sine opio 3 IIII ${ }^{\text {or }}>$.

Señor Madrid: mande dar al que esta le diere doss honzas de vngüente blanco y vna de rrosado.

Fecha en Valladolid, a veinte y ocho días de abril, 1563 años.

$<$ Yten olei rosarum 3 IIII ${ }^{\text {or }}>$. $<$ Aceite rosarum 3 I. Misce $>$.

El doctor Mançanedo (rúbrica).

$\S$ La trifera magna de arriba fue para enbiar a Santhelices.

\section{3}

Señor Madrid: mande dar dos honzas de açeite de alcaparras y onza y media de jasaue (sic) de borrajas. Que por esta yo la tomaré en qüenta.

Fecho a çinco de jullio de mill e quinientos e sesenta y tres años.

Doña Ysabel de Çeýnos (rúbrica).

El señor doctor Mançanedo.

\section{BIBLIOGRAFÍA}

AGAPITO Y REVILLA, J. Las calles de Valladolid: nomenclator histórico. Valladolid, Grupo Pinciano, 1982.

ALCOCER MARTÍNEZ, M. Historia de la Universidad de Valladolid. Bio-bibliografía de juristas notables. Valladolid, 1924.

—. Historia de la Universidad de Valladolid. Bio-bibliografías de médicos notables. Valladolid, 1931.

- Historia de la Universidad de Valladolid. Expedientes de provisiones de cátedras. Valladolid, [1921].

ARRIBAS GONZÁLEZ, S. - FEIJÓO CASADO, A.Mª (dirs.) Guía del Archivo de la Real Chancillería de Valladolid. Valladolid, Universidad de Valladolid: Secretariado de Publicaciones e Intercambio Científico, 1998.

CANONICA-DE ROCHEMONTEIX, E. El poliglotismo en el teatro de Lope de Vega. Kassel, Edition Reichenberger, 1991.

FERNÁNDEZ LUZÓN, A. La Universidad de Barcelona en el siglo XVI. Barcelona, Publicacions i Edicions de la Universitat de Barcelona, 2005.

FOLH JOU, G. "Medicamentos empleados por los árabes y su influencia en la Farmacia de Occidente, en especial española, desde el siglo XVI", en América y la España del siglo XVI. I: Madrid, CSIC. Instituto Fernández de Oviedo, 1982.

FRESQUET FEBRER, J.L. “Terapéutica y materia médica americana en la obra de Andrés Laguna (1555)”, Asclepio, XLIV-2 (1992).

GONZÁLEZ GARCÍA-VALLADOLID, C. Datos para la Historia Biográfica de la M.L.M.N.H. y Excma. ciudad de Valladolid. Valladolid, Imprenta y Librería 
Nacional y Extranjera de Hijos de Rodríguez, libreros de la Universidad y del Instituto, 1894.

GRANJEL, L.S. Cirugía Española del Renacimiento, Salamanca, Universidad de Salamanca, 1968.

LAGUNA, A. DE. Pedacio Dioscórides Anazarbeo, acerca de la Materia Medicinal, y de los venenos mortifèros. Traduzido de lengua Griega, en la vulgar Castellana, e illustrado con claras y substanciales Annotationes, y con las figuras de innumeras plantas exquisitas y raras, por el Doctor Andrés de Laguna. En Anuers, en casa de Iuán Latio, 1555. Edición facsímil, Madrid, 1991.

PASTOR FRECHOSO, F.F. Boticas, boticarios y materia médica en Valladolid (Siglos XVI y XVII). Salamanca, Junta de Castilla y León. Consejería de Cultura y Turismo, 1993.

PELÁEZ, M.J. (dir. y coord.) Diccionario crítico de juristas Españoles, Portugueses y Latinoamericanos (Hispánicos, Brasileños, Quebequenses y restantes francófonos). Zaragoza-Barcelona, 2006.

PESET, J.L. "La enseñanza de la Medicina y la Cirugía en el Antiguo Régimen”, en Historia y Medicina en España. Homenaje al profesor Luis S. Granjel. Valladolid, Junta de Castilla y León, 1994.

PUERTO SARMIENTO, F.J. "Los productos farmacéuticos de los siglos XVI y XVII", en El botamen de la farmacia del Hospital de Simón Ruiz en Medina del Campo, Valladolid, [2005].

ROJO VEGA, A. “Astrología judiciaria y esfera para médicos. Valladolid 1599”, Medicina \& Historia, 1 (2010).

—. "Los médicos vallisoletanos del siglo XVII. Status y consideración social”, en Historia y Medicina en España. Homenaje al profesor Luis S. Granjel. Valladolid, Junta de Castilla y León, 1994.

-. Ciencia y cultura en Valladolid. Estudio de las bibliotecas privadas de los siglos XVI y XVII. Valladolid: Universidad de Valladolid, 1985.

- Enfermos y sanadores en la Castilla del siglo XVI. Valladolid, Universidad de Valladolid: Secretariado de Publicaciones, 1993.

SIMÓN DÍAZ, J. Bibliografía de la Literatura Hispánica. Madrid, Instituto Miguel de Cervantes. Tomo XIV. CSIC, 1984.

VALDERAS, J.M. “Benedictus Textor y la enseñanza de la «Materia Médica» de Dioscorides”, Asclepio XLVII-1 (1995).

Fecha de recepción del artículo: febrero 2013

Fecha de aceptación y versión final: septiembre 2013 